\title{
Comparison of different gas models to calculate the spring force of a hydropneumatic suspension
}

\author{
S. Francois van der Westhuizen ${ }^{1}$ and P. Schalk Els ${ }^{1 *}$ \\ ${ }^{1}$ University of Pretoria, Corner of Lynnwood Road and Roper Street, Pretoria, 0002, South Africa \\ Department of Mechanical and Aeronautical Engineering, University of Pretoria, Private Bag X20, Hatfield 0028, South Africa
}

*Corresponding Author. Tel.: +27 12420 2045; fax: +27 123625087.

E-mail addresses: FrancoisVd@bell.co.za (S.F. van der Westhuizen), schalk.els@up.ac.za (P.S. Els).

\begin{abstract}
When developing any simulation model some compromise must be made between computational efficiency and the accuracy of the model. This study compares the performance of three ideal gas (IG) law variations (IG with the energy equation (EE), isothermal and adiabatic), and two real gas approaches (Benedict Webb Rubin (BWR) equation with and without the EE) to model the spring force of a hydropneumatic suspension. These models are compared with experimental data obtained from laboratory tests on a single hydropneumatic suspension unit. Both the BWR and IG models with the EE offer a significant improvement in correlation compared to the models without the EE. The real gas BWR approach offers a small improvement over the IG approach under the test conditions. The best (BWR with EE) and worst (IG isothermal) models are then used to model the spring forces in a full vehicle model of a $4 \times 4$ Sports Utility vehicle (SUV). The data is again compared with experimental results and the BWR model with the EE correlates significantly better than the IG isothermal model. It is thus concluded that the inclusion of the EE will yield significantly better results and it should only be omitted if the parameters investigated are not sensitive to errors in the spring model.
\end{abstract}

Keywords: Vehicle simulation, Hydropneumatic suspension, Suspension modelling, Spring modelling, Gas modelling, Model verification, Energy equation, Benedict Webb Rubin, Real gas

\section{Introduction}

Using modern day technology a design can be verified and adjusted before production, by using simulation models. Due to the complexity of highly detailed models a compromise is often made between ease of use, computational efficiency and model accuracy. Full vehicle models often contain a large number of sub-models. This means that a small error in the results of a sub-model can have a significant effect on the overall result. This also allows for the possibility of a model working well for a certain case due to the effect of the errors being small or due to the errors cancelling out and thus having a small net effect. The result is that the model will not give good results when modelling other cases. This is emphasised by [1] who states that simulations offer great advantages over physical prototypes, but in order to obtain meaningful results the model should be validated using the correct parameters. Bernard and Clover [2] define validation within the context of vehicle simulation as: "the process of gaining confidence that the calculations yield useful insight into the behaviour of the simulated vehicle."

Hydropneumatic suspensions are widely used in off road applications due to the ease with which the characteristics can be changed. According to [3] almost every suspended tractor front axle uses hydropneumatics. The Dynamic Truck Suspension by Vehicle Systems Engineering (VSE) [4] is another example of a hydropneumatic suspension used for military and off road rally applications. Large construction vehicles, e.g. dump trucks, often use hydropneumatic suspension systems due to the high energy density, and thus small space requirements compared to steel springs and dampers. Thus to build an accurate vehicle dynamics model of these vehicles, a good hydropneumatic suspension model is necessary. During a study on slow active suspension control of a hydropneumatic suspension by [5] some concerns were expressed regarding the accuracy of the Ideal Gas (IG) law to model the spring. In this study it was decided to rather use a real gas approach which should be more accurate than the IG approach, but the validity of this assumption has not been verified. This study will therefore quantify the accuracy gained by using a real gas approach with and without heat transfer compared to an IG approach with and without heat transfer. The best and worst models are then used to model the spring in a full vehicle model and the results are compared with experimental data. 
The suspension used in this study is the $4 \mathrm{~S}_{4}$ (4 State Semi-active Suspension System) developed by [6]. A schematic diagram of a $4 \mathrm{~S}_{4}$ unit can be seen in Figure 1. It consists of two hydropneumatic springs combined with two hydraulic dampers. If valve 3 is closed only the small gas volume in accumulator 1 is compressed resulting in a stiff spring characteristic. If valve 3 is open the larger gas volume in both accumulators are compressed resulting in a soft spring characteristic. If valves 1 and 2 are closed the system delivers high damping and low damping if they are open. The volume of accumulator 1 and the damping characteristics of damper 1 have been optimised for handling by minimising the body roll angle when performing a severe double lane change (DLC) manoeuvre. This represents the "handling" setting. The combined gas volumes of accumulators 1 and 2, as well as the combined characteristics of dampers 1 and 2, with valve 1 and 2 open, have been optimised to minimise the vertical acceleration on the vehicle whilst driving over rough Belgian paving terrain. This represents the "ride comfort" setting. The $4 \mathrm{~S}_{4}$ can switch between "handling" and "ride comfort" settings in less than 100 milliseconds. Switching between the different settings occur automatically based on acceleration measured on the vehicle body. The switching is performed by opening or closing solenoid valves. This suspension has been implemented successfully on a Land Rover Defender 110 at the University of Pretoria. Take note that the dampers shown in Figure 1 were removed for the gas model validations described in section 3.2 .

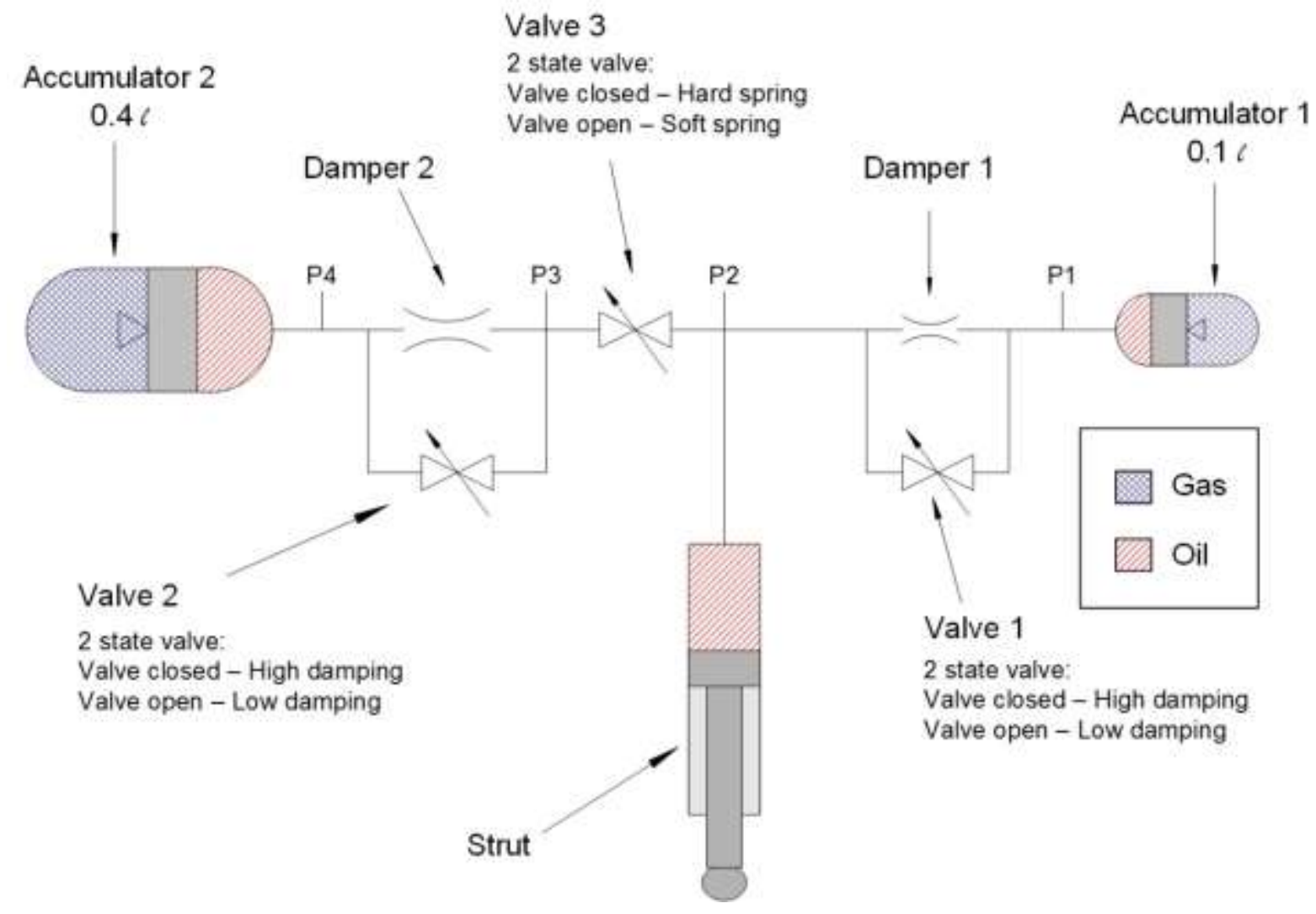

Figure 1 Schematic diagram of the $4 S_{4}$

\section{Mathematical modelling}

\subsection{Modelling of hydropneumatic springs}

In order to obtain realistic vehicle dynamics simulation results when considering different suspension characteristics or control algorithms, an accurate suspension model is required. The spring force in a hydropneumatic suspension is generated by compressing gas and it is thus expected that the spring force can be calculated using gas laws. The gas used in the majority of hydropneumatic springs is Nitrogen $\left(\mathrm{N}_{2}\right)$ because it is inert, generally available and does not pose an explosion risk.

Deprez et al. [7] models a hydropneumatic spring using the adiabatic variation of the IG law. There is however no comparison to experimental results. Cooke et al. [8] also models a hydropneumatic suspension but assumes it to have linear rates and also does not verify the results with experimental data. According to [3] hydropneumatic 
springs have a progressive force - displacement relationship, caused by the physical laws for a polytropic change of state of a gas. From this statement it can be perceived that linear assumptions will not return realistic results, therefore linear methods will not be investigated. According to [9] the temperature of a nitrogen accumulator can drop from ambient to $200 \mathrm{~K}$ during expansion. A temperature change of this magnitude can have a significant effect on the characteristics of a hydropneumatic spring. It is also shown that a hysteresis loop exists on the pressure - volume diagram that cannot be explained using a single polytropic exponent, therefore an algorithm that incorporates real gas properties is proposed. It is concluded that using a thermal time constant is superior to using a polytropic exponent, because a polytropic exponent cannot explain the hysteresis loop unless it is varied in some way. This study was done for a relatively large accumulator with a gas volume of $2.5 \ell$, which is unrealistically large for Sport Utility Vehicles (SUV) or passenger vehicles, and although good results are obtained there is uncertainty whether this will give good results at smaller volumes.

According to [10] hydropneumatic spring characteristics can be approximated with a polytropic IG process, which is often found in literature, but this approach assumes that the polytropic constant, $n$, is constant which is not the case in reality. This adds to the errors already included by assuming the gas to be ideal. The study also shows that the compressibility factor for the IG approach can vary between 0.92 and 1.5 for the typical range of use of a hydropneumatic spring on heavy vehicles where high gas pressures are used. It is further found that the temperature rise in a hydropneumatic suspension can have a significant effect on the characteristics of the spring. The proposed method of [9] is therefore expanded to model a hydropneumatic spring. The model implements the Benedict-Webb-Rubin (BWR) real gas equation in conjunction with the energy equation (EE) for a closed system, to model the response of the nitrogen.

The simplest gas law is the IG law, but the IG law does not take intermolecular forces at small intermolecular distances into account. It therefore over estimates the compressibility at either high pressures or low temperatures [11], of which both might be present when working with hydropneumatic springs. Since the IG approach is more computationally efficient than a real gas approach and easier to implement, it would be desirable to use an IG approach provided that the accuracy is sufficient. With both the IG and real gas approaches an isothermal approach can be followed where the change in temperature is assumed to be negligibly small, or the first law of thermodynamics can be used to take the change in temperature into account. By taking the change in temperature into account complexity is again added to the system and the model will take longer to solve.

\subsubsection{Ideal gas approach}

The IG law is stated in Equation 1:

$P=\frac{m R T_{g}}{V}$ or $P=\frac{R T_{g}}{v}$

For gas in a closed system, the mass, $m$, and the universal gas constant, $\mathrm{R}$, will be constant. If the gas is, for example, compressed from state 1 to state 2, Equation 1 can be re-written as:

$\frac{P_{1} V_{1}}{T_{1}}=\frac{P_{2} V_{2}}{T_{2}}$

If the temperature is constant during this compression $\left(T_{1}=T_{2}\right)$ it is an isothermal process and the following relation can be used:

$P_{1} V_{1}=P_{2} V_{2}$

If the temperature is not constant during this compression, the process can be modelled using a polytropic relation as shown in Equation4:

$P_{1} V_{1}^{n}=P_{2} V_{2}^{n}$

A polytropic constant $(n)$ of 1 will yield an isothermal process while $1<n<\gamma$ will yield a polytropic process. If $n=\gamma$ ( $\gamma$ is the adiabatic index of the gas) it will yield an adiabatic process where no heat transfer between the gas and its surroundings takes place. The adiabatic index for air and nitrogen is $\gamma \approx 1.4$.

\subsubsection{Real gas approach}

There are several real gas equations available, each with its own region of applicability. The Benedict-WebbRubin (BWR) equation is stated by [6] to be appropriate for use in the typical operating temperature and 
pressure ranges required for hydropneumatic springs. The BWR real gas approach adds corrective terms to the IG law to predict the gas characteristic more accurately as can be seen in Equation 5. The BWR constants for nitrogen are given in Appendix A.

$P=\frac{R T_{g}}{v}+\left\{\frac{B_{o} R T_{g}-A_{o}-\frac{C_{o}}{T_{g}^{2}}}{v^{2}}+\frac{b R T_{g}-a}{v^{3}}+\frac{a \alpha}{v^{6}}+\frac{c\left(1+\frac{\gamma}{v^{2}}\right)}{v^{3} T_{g}^{2}}\right\}$

\subsubsection{Energy equation approach}

If significant heat transfer takes place between the gas and its surroundings, it can be taken into account using the energy equation (EE or first law of thermodynamics) for a closed system (Equation 6):

$\dot{\mathrm{U}}=\dot{\mathrm{Q}}-\dot{\mathrm{W}} \quad$ or $\quad m \dot{u}=\dot{\mathrm{Q}}-\dot{\mathrm{W}}$

In order to apply the method used by [9] to model a hydropneumatic spring, [10] makes the following assumptions:

i. The system is a closed system.

ii. No inertia effects are present during the gas compression.

iii. The process is seen as a homogeneous, quasi-static gas compression process.

iv. The effect of the thermal capacity of the piston rod and that of the cylinder wall is seen as negligibly small.

The convective heat transfer between the spring and the environment can be approximated by:

$\dot{\mathrm{Q}}=\frac{\mathrm{mc} \mathrm{c}_{v}\left(\mathrm{~T}_{\mathrm{s}}-\mathrm{T}_{\mathrm{g}}\right)}{\tau}$

The thermal time constant, $\tau$, can be defined as the time it takes the gas temperature to reduce by $63 \%$ of the difference between the temperature after being compressed rapidly and the steady state (ambient) temperature.

The rate of the piston work is given by:

$\dot{\mathrm{W}}=\mathrm{P} \dot{\mathrm{V}}$

The internal energy per unit mass is given by the thermodynamic relation:

$\mathrm{du}=\mathrm{c}_{v} \mathrm{dT}_{\mathrm{g}}+\left[\mathrm{T}_{\mathrm{g}}\left(\frac{\partial \mathrm{P}}{\partial \mathrm{T}_{\mathrm{g}}}\right)_{v}-\mathrm{P}\right] \mathrm{d} v$

Substituting Equations (7), (8) and (9) into (6) gives:

$\mathrm{m}\left[\mathrm{c}_{v} \mathrm{dT}_{\mathrm{g}}+\left[\mathrm{T}_{\mathrm{g}}\left(\frac{\partial \mathrm{P}}{\partial \mathrm{T}_{\mathrm{g}}}\right)_{v}-\mathrm{P}\right] \mathrm{d} v\right]=\frac{\mathrm{mc}_{\mathrm{v}}\left(\mathrm{T}_{\mathrm{s}}-\mathrm{T}_{\mathrm{g}}\right)}{\tau}-\mathrm{P} \dot{\mathrm{V}}$

which can be simplified to:

$\mathrm{mc}_{v} \dot{\mathrm{T}}_{\mathrm{g}}+\mathrm{m}\left[\mathrm{T}_{\mathrm{g}}\left(\frac{\partial \mathrm{P}}{\partial \mathrm{T}_{\mathrm{g}}}\right)_{v}-\mathrm{P}\right] \dot{v}=\frac{\mathrm{mc}_{v}\left(\mathrm{~T}_{\mathrm{s}}-\mathrm{T}_{\mathrm{g}}\right)}{\tau}-\mathrm{PV}$

and divided with $\mathrm{mc}_{\mathrm{v}}$ to give:

$\dot{\mathrm{T}}_{\mathrm{g}}+\frac{\mathrm{T}_{\mathrm{g}}\left(\frac{\partial P}{\partial \mathrm{T}_{\mathrm{g}}}\right)_{v}^{\dot{v}}}{\mathrm{c}_{v}}-\frac{\mathrm{P} \dot{v}}{\mathrm{c}_{v}}=\frac{\left(\mathrm{T}_{\mathrm{s}}-\mathrm{T}_{\mathrm{g}}\right)}{\tau}-\frac{\mathrm{P} \dot{V}}{\mathrm{mc}_{v}}$

Knowing that $\dot{V}=m \dot{v}$, the differential equation simplifies to:

$\dot{\mathrm{T}}_{\mathrm{g}}=\frac{\left(\mathrm{T}_{\mathrm{s}}-\mathrm{T}_{\mathrm{g}}\right)}{\tau}-\frac{\mathrm{Tg}\left(\frac{\partial \mathrm{P}}{\partial \mathrm{Tg}}\right)_{v} \dot{v}}{\mathrm{c}_{v}}$

The BWR equation is used to represent the $\mathrm{P}-v-\mathrm{T}$ relationship: 
$\mathrm{P}=\frac{\mathrm{RT}_{\mathrm{g}}}{v}+\frac{\mathrm{B}_{\mathrm{O}} \mathrm{RTg}_{\mathrm{g}}-\mathrm{A}_{\mathrm{o}}-\frac{\mathrm{C}_{0}}{\mathrm{~T}_{\mathrm{g}}^{2}}}{v^{2}}+\frac{\mathrm{bRT}_{\mathrm{g}}-\mathrm{a}}{v^{3}}+\frac{\mathrm{a} \alpha}{v^{6}}+\frac{\mathrm{c}\left(1+\frac{\gamma}{v^{2}}\right) \mathrm{e}^{\frac{-\gamma}{v^{2}}}}{v^{3} \mathrm{~T}_{\mathrm{g}}^{2}}$

Differentiating (11) in terms of $\mathrm{T}$ results in:

$\left(\frac{\partial \mathrm{P}}{\partial \mathrm{T}_{\mathrm{g}}}\right)_{v}=\frac{\mathrm{R}}{v}+\frac{\mathrm{B}_{\mathrm{o}} \mathrm{R}}{v^{2}}+\frac{2 \mathrm{C}_{\mathrm{o}}}{\mathrm{T}_{\mathrm{g}}^{3} v^{2}}+\frac{\mathrm{bR}}{v^{3}}-\frac{2 \mathrm{c}\left(1+\frac{\gamma}{v^{2}}\right) \mathrm{e}^{\frac{-\gamma}{v^{2}}}}{v^{3} \mathrm{~T}_{\mathrm{g}}^{3}}$

Replacing (12) into (10) gives:

$\dot{\mathrm{T}}_{\mathrm{g}}=\frac{\left(\mathrm{T}_{\mathrm{s}}-\mathrm{T}_{\mathrm{g}}\right)}{\tau}-\frac{\dot{v}}{c_{v}}\left[\frac{\mathrm{TgR}_{\mathrm{g}}}{v}+\frac{\mathrm{Tg}_{\mathrm{g}} \mathrm{B}_{\mathrm{o}}}{v^{2}}+\frac{2 \mathrm{C}_{\mathrm{o}}}{\mathrm{T}_{\mathrm{g}}^{2} v^{2}}+\frac{\mathrm{Tg} \mathrm{bR}}{v^{3}}-\frac{2 \mathrm{c}\left(1+\frac{\gamma}{v^{2}}\right) \mathrm{e}^{\frac{-\gamma}{v^{2}}}}{v^{3} \mathrm{~T}_{\mathrm{g}}^{2}}\right]$

Which can be regrouped to give:

$\dot{\mathrm{T}}_{\mathrm{g}}=\frac{\left(\mathrm{T}_{\mathrm{s}}-\mathrm{T}_{\mathrm{g}}\right)}{\tau}-\frac{\dot{v}}{\mathrm{c}_{v}}\left[\frac{\mathrm{T}_{\mathrm{g}} \mathrm{R}}{v}\left(1+\frac{\mathrm{b}}{v^{2}}\right)+\frac{1}{v^{2}}\left(\mathrm{~T}_{\mathrm{g}} \mathrm{B}_{\mathrm{o}} \mathrm{R}+\frac{2 \mathrm{C}_{\mathrm{o}}}{\mathrm{T}_{\mathrm{g}}^{2}}\right)-\frac{2 \mathrm{c}}{v^{3} \mathrm{~T}_{\mathrm{g}}^{2}}\left(1+\frac{\gamma}{v^{2}}\right) \mathrm{e}^{\frac{-\gamma}{v^{2}}}\right]$

$[9,11]$

Equation 13 is a first order differential equation that can be solved numerically by means of the 4th order Runge Kutta method. [12]

The ideal gas specific heat is given by:

$c_{v}^{0}=R\left[\frac{\mathrm{N}_{1}}{\mathrm{~T}_{\mathrm{g}}^{3}}+\frac{\mathrm{N}_{2}}{\mathrm{~T}_{\mathrm{g}}^{2}}+\frac{\mathrm{N}_{3}}{\mathrm{~T}_{\mathrm{g}}}+\left(\mathrm{N}_{4}-1\right)+\mathrm{N}_{5} \mathrm{~T}_{\mathrm{g}}+\mathrm{N}_{6} \mathrm{~T}_{\mathrm{g}}^{2}+\mathrm{N}_{7} \mathrm{~T}_{\mathrm{g}}^{3}+\frac{\mathrm{N}_{8} \mathrm{y}^{2} \mathrm{e}^{\mathrm{y}}}{\left(\mathrm{e}^{\mathrm{y}}-1\right)^{2}}\right]$

Where:

$\mathrm{y}=\frac{\mathrm{N}_{9}}{\mathrm{~T}_{\mathrm{g}}}$

Knowing $\mathrm{c}_{\mathrm{v}}^{0}$ the specific heat for the real gas $\left(\mathrm{c}_{\mathrm{v}}\right)$ can be calculated:

$\mathrm{c}_{v}=\mathrm{c}_{v}^{0}+\frac{6}{\mathrm{~T}_{\mathrm{g}}^{3}}\left(\frac{\mathrm{c}_{\mathrm{o}}}{v}-\frac{\mathrm{c}}{\gamma}\right)+\frac{3 \mathrm{c}}{\mathrm{T}_{\mathrm{g}}^{3}}\left(\frac{2}{\gamma}-\frac{1}{v^{2}}\right) \mathrm{e}^{\left(-\frac{\gamma}{v^{2}}\right)}$

The constants for the BWR equation and $\mathrm{N}_{1}$ to $\mathrm{N}_{9}$ can be found in Appendix A.

Table 1 Comparison of the EE for the BWR and IG model

\begin{tabular}{|c|c|}
\hline Real Gas (BWR) & Ideal Gas \\
\hline$\dot{U}=\dot{Q}-\dot{W}$ & $\mathrm{~m} \dot{\mathrm{u}}=\dot{\mathrm{Q}}-\dot{\mathrm{W}}$ \\
\hline$\dot{\mathrm{Q}}=\frac{\mathrm{mc}_{v}\left(\mathrm{~T}_{\mathrm{s}}-\mathrm{T}_{\mathrm{g}}\right)}{\tau}$ & $\dot{\mathrm{Q}}=\frac{\mathrm{mc}_{v}^{\mathrm{o}}\left(\mathrm{T}_{\mathrm{s}}-\mathrm{T}_{\mathrm{g}}\right)}{\tau}$ \\
\hline \multicolumn{2}{|l|}{$\dot{\mathrm{W}}=\mathrm{P} \dot{\mathrm{V}}$} \\
\hline $\mathrm{du}=\mathrm{C}_{v} \mathrm{dT}_{\mathrm{g}}+\left[\mathrm{T}_{\mathrm{g}}\left(\frac{\partial \mathrm{P}}{\partial \mathrm{T}_{\mathrm{g}}}\right)_{v}-\mathrm{P}\right] \mathrm{d} v$ & $\begin{array}{l}\mathrm{du}=\mathrm{C}_{v \mathrm{o}} \mathrm{dT}_{\mathrm{g}} \quad \text { (Effect of Pressure is neglected) } \\
{[11]}\end{array}$ \\
\hline $\mathrm{m}\left[\mathrm{C}_{v} \mathrm{dT}_{\mathrm{g}}+\left[\mathrm{T}_{\mathrm{g}}\left(\frac{\partial \mathrm{P}}{\partial \mathrm{T}_{\mathrm{g}}}\right)_{v}-\mathrm{P}\right] \mathrm{d} v\right]=\frac{\mathrm{mC}_{v}\left(\mathrm{~T}_{\mathrm{s}}-\mathrm{T}_{\mathrm{g}}\right)}{\tau}-\mathrm{PV}$ & $\mathrm{mC}_{v 0} \mathrm{dT}_{\mathrm{g}}=\frac{\mathrm{mC}_{v 0}\left(\mathrm{~T}_{\mathrm{s}}-\mathrm{T}_{\mathrm{g}}\right)}{\tau}-\mathrm{PV}$ \\
\hline $\begin{array}{c}\dot{\mathrm{T}}_{\mathrm{g}}=\frac{\left(\mathrm{T}_{\mathrm{s}}-\mathrm{T}_{\mathrm{g}}\right)}{\tau}-\frac{\dot{v}}{\mathrm{c}_{v}}\left[\frac{\mathrm{T}_{\mathrm{g}} \mathrm{R}}{v}\left(1+\frac{\mathrm{b}}{v^{2}}\right)+\frac{1}{v^{2}}\left(\mathrm{~T}_{\mathrm{g}} \mathrm{B}_{\mathrm{o}} \mathrm{R}+\frac{2 \mathrm{C}_{\mathrm{o}}}{\mathrm{T}_{\mathrm{g}}^{2}}\right)\right. \\
\left.-\frac{2 \mathrm{c}}{v^{3} \mathrm{~T}_{\mathrm{g}}^{2}}\left(1+\frac{\gamma}{v^{2}}\right) \mathrm{e}^{\frac{-\gamma}{v^{2}}}\right]\end{array}$ & $\dot{\mathrm{T}}_{\mathrm{g}}=\frac{\left(\mathrm{T}_{\mathrm{s}}-\mathrm{T}_{\mathrm{g}}\right)}{\tau}-\frac{\mathrm{P} \dot{v}}{\mathrm{C}_{v 0}}$ \\
\hline $\mathrm{P}=\frac{\mathrm{RT}_{\mathrm{g}}}{v}+\frac{\mathrm{B}_{\mathrm{o}} \mathrm{RT}_{\mathrm{g}}-\mathrm{A}_{\mathrm{o}}-\frac{\mathrm{C}_{\mathrm{o}}}{\mathrm{T}_{\mathrm{g}}^{2}}}{v^{2}}+\frac{\mathrm{bRT} \mathrm{T}_{\mathrm{g}}-\mathrm{a}}{v^{3}}+\frac{\mathrm{a} \alpha}{v^{6}}+\frac{\mathrm{c}\left(1+\frac{\gamma}{v^{2}}\right) \mathrm{e}^{\frac{-\gamma}{v^{2}}}}{v^{3} \mathrm{~T}_{\mathrm{g}}^{2}}$ & $\mathrm{P}=\frac{\mathrm{RT}_{\mathrm{g}}}{v}$ \\
\hline
\end{tabular}


Similarly the EE can be used with the IG law. Table 1 compares the energy equation formulations for the real gas and ideal gas approaches.

\subsection{Suspension model}

The total suspension force in a vehicle suspension system generally consists of four components namely: damper force, friction force, spring force and bump stop force. The suspension model used in this study is described using Figure 2 and forms part of a full vehicle model (of the mentioned Land Rover Defender 110) that was developed and validated by [13]. The suspension is modelled using Matlab/Simulink [14, 15] and provides the ADAMS/View [16] vehicle model with a suspension force via co-simulation. Modelling of the spring force has been described in paragraph 2.1. The damper force is determined using a lookup table with experimentally determined data, where the force is a function of velocity. Friction is determined using a lookup table giving friction force as a function of velocity. The effect of the bump stops is modelled using first order polynomials giving the bump stop force as a function of displacement. The force generated by the gas spring is the topic of this study and is calculated using either the IG equation or the BWR real gas equation both with and without the EE. The gas model receives a suspension displacement value from the ADAMS/View vehicle model and then calculates the spring force.

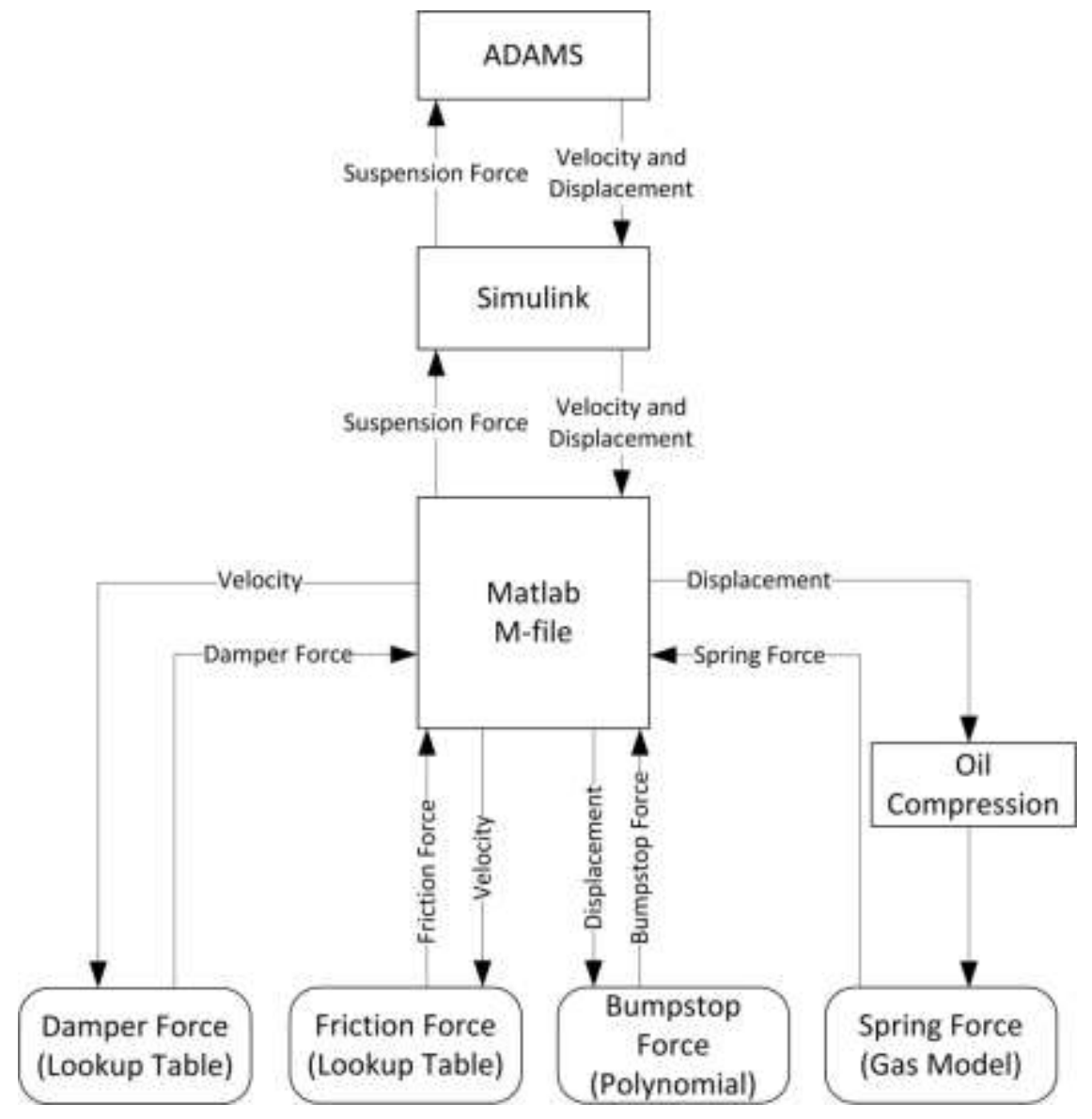

Figure 2 Suspension model interaction

Els [6] has found that assuming the oil, in a hydropneumatic suspension, to be incompressible can yield significant errors. Therefore this model also takes the compressibility of the oil into account by means of an experimentally determined bulk modulus $(\beta=1.368 \mathrm{GPa},[6])$ and Equation 14. The oil temperature is assumed to be constant due to the short time periods over which the tests took place. The main cause for oil temperature change is the energy dissipated in the damper. This is one of the reasons that the dampers shown in Figure 1 were removed for the gas model validations described in section 3.2.

$\Delta V=\left(\frac{\Delta P}{\beta}\right) V_{o}$ 


\subsection{Vehicle model}

The full vehicle model of the Land Rover Defender 110 test vehicle used in this study was developed by [13] in ADAMS/View. This model has 15 unconstrained degrees of freedom. It also has 16 moving parts, 6 spherical joints, 8 revolute joints, 7 Hooke's joints and a motion defined by the steering driver. The model was modified by [17], [18] and [19] to add additional changes made to the test vehicle. Schematic diagrams of the front and rear suspension layouts are indicated in Figure 3 and Figure 4. The model makes use of the Pacejka '89 tyre model [20]. The longitudinal behaviour of the tyre and vehicle is not taken into account to make the model less computationally expensive. The more important vertical and lateral dynamics are however taken into account.

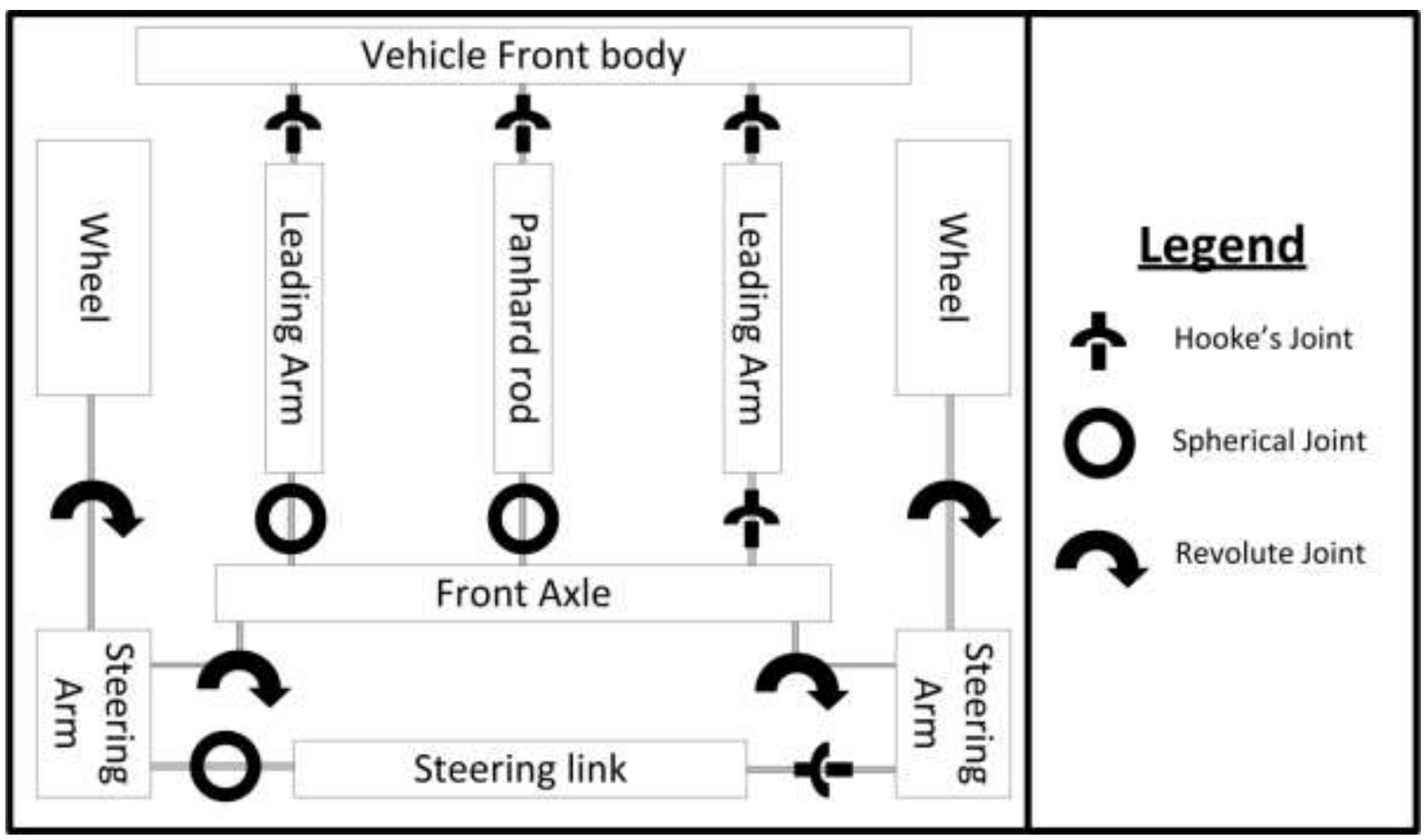

Figure 3 Schematic of the front suspension [13]

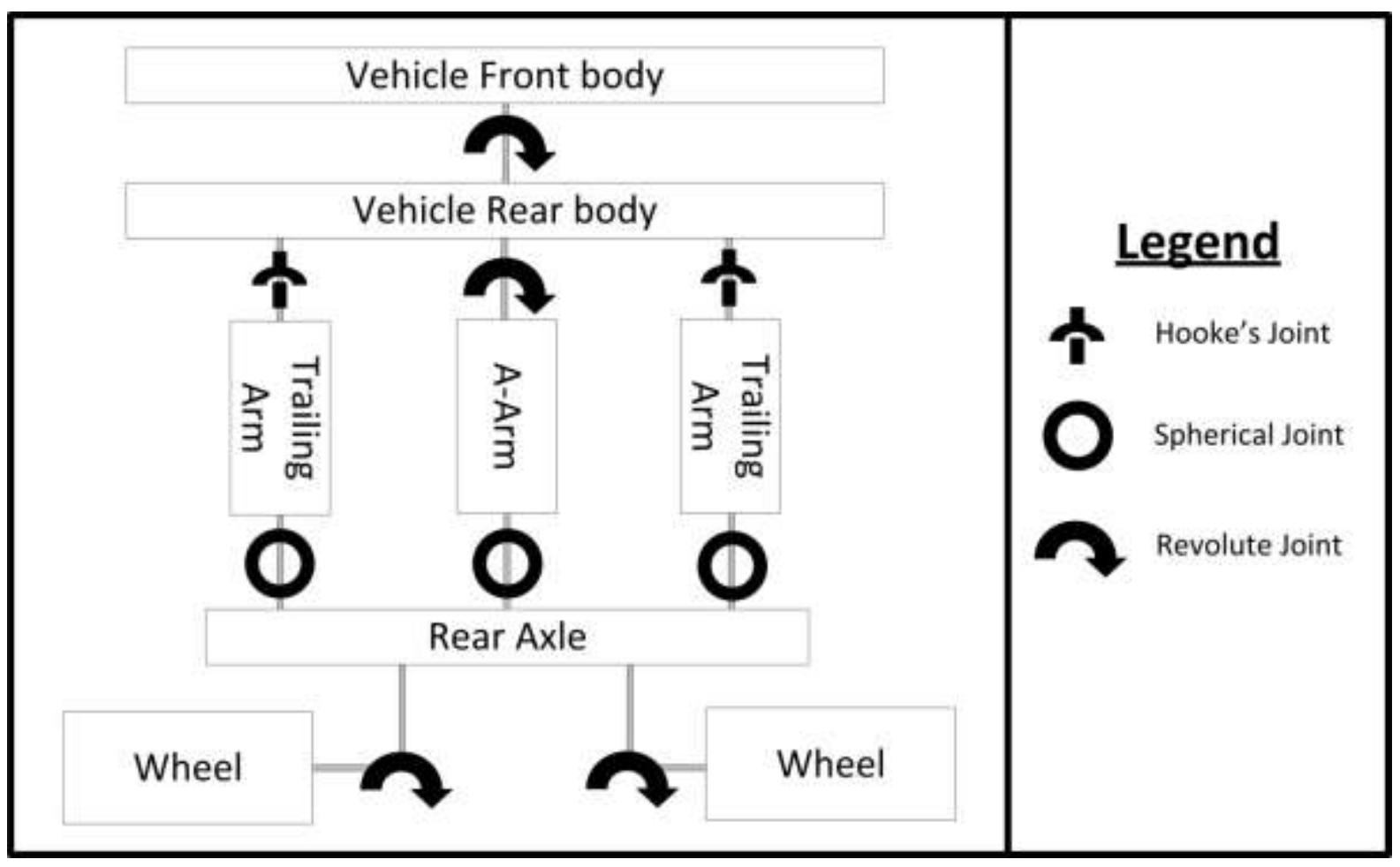

Figure 4 Schematic of the rear suspension [13] 


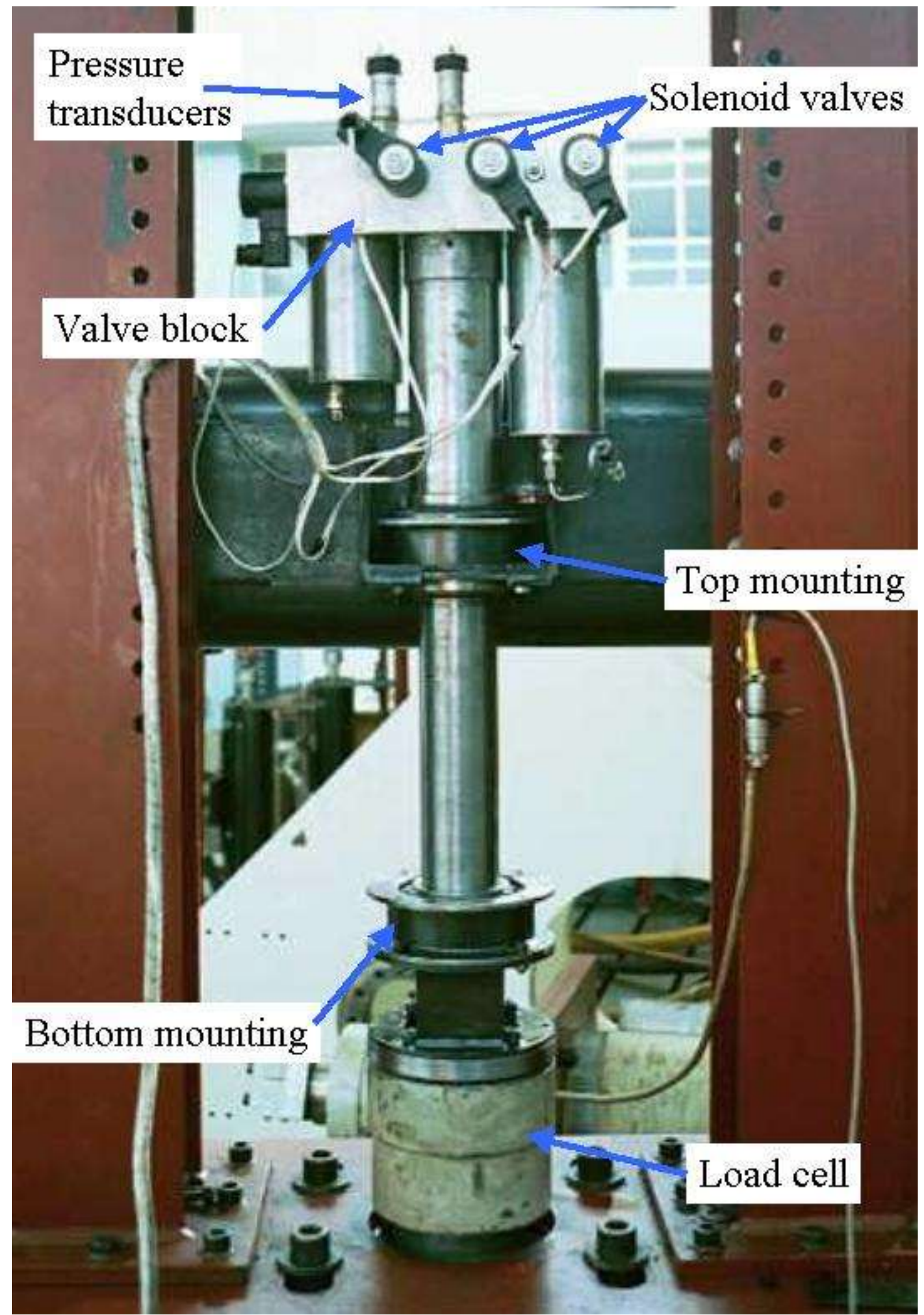

Figure 5 Experimental Test Setup

The body torsion is taken into account by dividing the vehicle body in two rigid bodies and connecting them with a revolute joint and a torsional spring. The suspension bushings are modelled using kinematic joints with 
torsional spring characteristics. The CG and moments of inertia have been determined experimentally and are also incorporated in the model [21].

The ADAMS/View model is linked with Simulink and Matlab using the ADAMS/Controls interface. Adams/View exports the vehicle dynamics variables to Simulink. These variables are then used to calculate the suspension forces which are sent back to ADAMS/View via Simulink (Figure 2).

The model has been fully validated against 16 measured channels during experimental testing and very good correlation was obtained. The vertical ride verification was done by driving over discrete bumps and the dynamic handling verification was done by performing a double lane change (DLC) at $65 \mathrm{~km} / \mathrm{h}[13]$.

\section{Simulation and experimental results}

\subsection{Laboratory tests}

Experimental data was obtained on a $4 \mathrm{~S}_{4}$ spring-damper to verify the mathematical models. The test setup consisted of a test frame mounted on a 100kN SCHENCK hydropulse actuator as shown in Figure 5. The actuator was operated in displacement control mode. The suspension unit was instrumented with four pressure transducers (P1 to P4 in Figure 1) to determine the dynamic system pressures. The force and displacement of the actuator was also measured by means of a load cell and linear displacement transducer. In order to reduce the number of external factors included in the experimental results, including temperature change, the suspension was characterised without the damper packs. Although this eliminates pressure drops over the damper packs, there are still pressure drops through the solenoid valves and the valve block channels. There are also some friction forces present in the experimental setup due to the friction between the floating piston of the accumulator and the cylinder wall. This friction force accounts for a component of the hysteresis loop seen in the pressure - displacement graphs.

The spring characteristics are strongly dependent on the mass of gas in each accumulator. It is therefore imperative that, before testing begins, the correct mass of gas is charged into each accumulator. This requires knowledge of the gas temperature, pressure and accumulator volume. Before gas is charged, it must be ensured that the unit is properly filled with oil and that enough time has lapsed so that air can escape from the oil.

The accumulators are charged from a high pressure nitrogen cylinder through a regulator. The gas temperature drops during expansion through the regulator and the temperature of the gas entering the accumulator is significantly lower than ambient. The gas is therefore charged very slowly to give enough time for the gas temperature inside the accumulator to reach ambient temperature.

The pressure in the accumulator is not measured directly. Instead the force on the piston rod or pressure P2 (Figure 1) is measured and used in the gas charging procedure. Friction in the accumulator piston seals results in a difference between the measured and the true accumulator pressures.

The gas volume is a direct function of the displacement of the accumulator piston. When the accumulator piston is pushed against its end stop in compression, the gas volume is however not zero due to gaps in the seals, small annular spaces between the piston and the cylinder and the volume inside the gas charging ports and valve. This residual volume is difficult to calculate or measure accurately. Furthermore the displacement of the accumulator piston is not measured directly but rather inferred from the displacement of the piston rod. This causes some uncertainty as the bulk modulus of the fluid and the air trapped in the oil needs to be taken into account.

Due to all these factors it should be acknowledged that, although every attempt is made during the gas charging procedure to charge the correct mass of gas, there are several uncertainties in the process that lead to a final mass of gas that can differ significantly from the nominal design value. Although these uncertainties could largely be eliminated by measuring the temperature and pressure inside each accumulator, as well as the displacement of each accumulator piston, this adds extensive cost and complexity to the system and is not feasible for implementation in practice.

\subsection{Spring models}

Five different gas models were used to model the hydropneumatic spring force. Simulation results, when the spring force is calculated using the five different approaches formulated in par. 2.1, are now compared to both laboratory and vehicle test data. Three variations of the IG law (Equation 1) are used; one for an isothermal process (Equation 3), one for an adiabatic process (Equation 4) and in the third model the IG law is used in conjunction with the EE (see Table 1). The other two models use the BWR real gas equation (Equation 5), one 
with the EE (Equation 13) and one where the temperature is kept constant (isothermal). The gas used is nitrogen and the adiabatic constant is taken as 1.4. The nominal design volumes of the $4 \mathrm{~S}_{4}$ are taken as $0.1 \ell\left(0.1 \times 10^{-3}\right.$ $\mathrm{m}^{3}$ ) for the stiff spring (accumulator 1) and as $0.5 \ell$ for the soft spring (accumulators 1 and 2 combined).

The gas charging procedure results in some uncertainty as to the exact static gas volume as discussed in par. 3.1. For the specific series of tests discussed in this paper, it was found by trial and error that a volume of $0.13 \ell$ for the small accumulator gave the best correlation between the measured and simulated results. The thermal time constants were experimentally determined by giving the suspension a step displacement input while measuring the pressure. Although the thermal time constant is a function of temperature, pressure can be used to determine if the gas is assumed to be ideal, and thus to have a linear relationship between pressure and temperature. This was done seeing that it is easier to measure pressure accurately with quick response times than to measure temperature. The tests yielded a $\tau$ of $4.82 \mathrm{~s}$ for the stiff spring (accumulator 1) and as $8.05 \mathrm{~s}$ for the soft spring (accumulator 1 and 2). Figure 6a indicates a finite volume ramp input which is used to show the effect of the EE on the stiff spring models (Figure 6b). The effect of the thermal time constant is clearly visible in the way that the pressure decreases to find a steady state after the ramp input in both models with the EE. This is due to the heat being dissipated trough the cylinder walls. The adiabatic model assumes no heat transfer takes place with the surroundings and therefore the pressure rises rapidly while work is being done on the system and then stays constant after the ramp input. The isothermal model assumes infinitely high heat transfer so that the gas temperature will stay constant and therefore the pressure rise is the lowest of all the models and stays constant after the ramp input. In Figure 7, an increasing frequency sine wave is used to show how the spring pressure will rise due to insufficient time for total heat dissipation. The sine wave is used here as it gives smooth transitions as the frequency increases compared to the triangular wave used later in par. 3.3. As the frequency increases the effect of the EE becomes visible as the forces become higher due to the temperature rise in the gas. At low frequencies a large amount of heat transfer takes place due to the large amount of time each cycle takes, approaching isothermal conditions. At high frequencies there is little time for heat transfer to take place and therefore this case will approach adiabatic conditions.

(a)

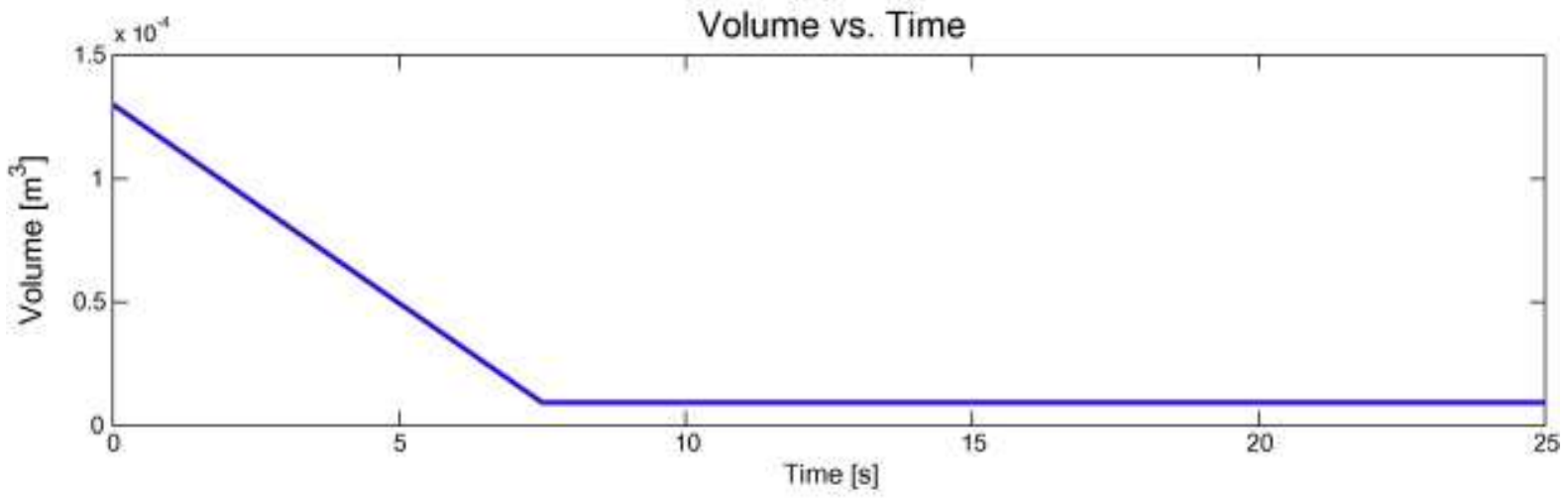

(b)

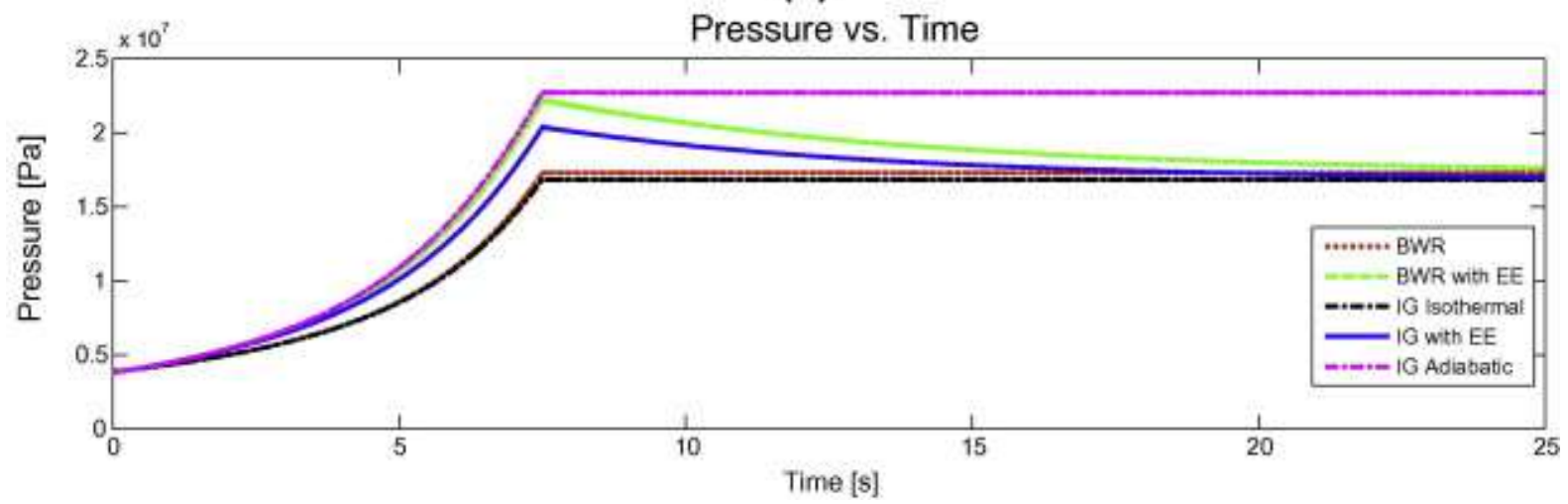

Figure 6 Response of the different gas models to finite change in volume 

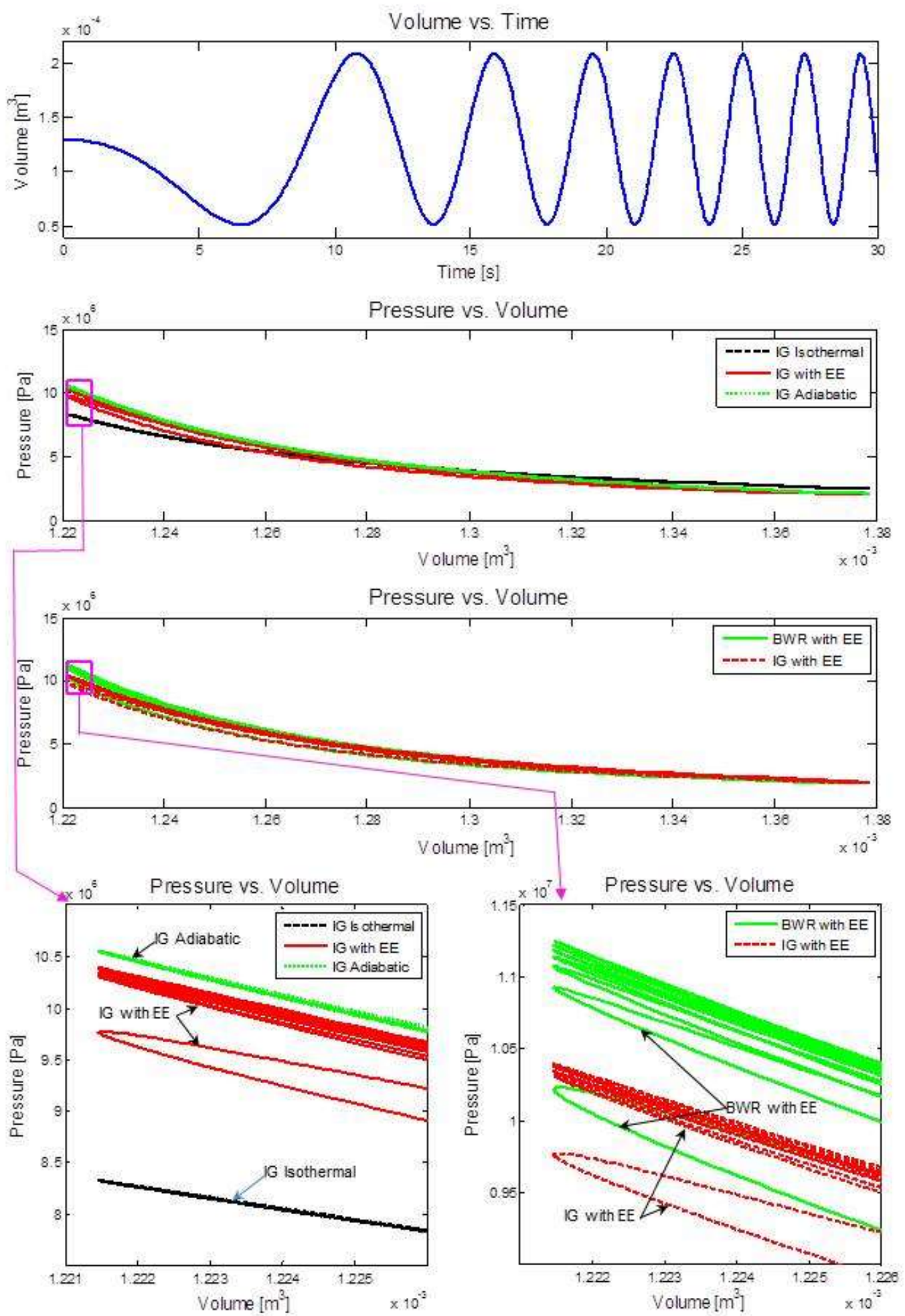

Figure 7 Response of the different gas models to an increasing frequency sine wave input 


\subsection{Spring model validation against laboratory results}

It is very difficult to quantify the quality of a model seeing that various factors play a role. In order to objectively quantify the quality of a model [1] proposed the use of a validation metric based on the modified percentage relative error $\left(\mathrm{m} \% \mathrm{RE}^{\mathrm{m}}\right)$ given with its probability $(\mathrm{P}(\%))$. Two variants of this method are proposed, the mean $\mathrm{m} \% \mathrm{RE}\left(\mathrm{m} \% \mathrm{RE}^{\mathrm{m}}\right)$ variant will be used in this study seeing that this method is proposed for model comparison. The $\mathrm{m} \% \mathrm{RE}^{\mathrm{m}}$ threshold is chosen as $100 \%$. This validation metric will give a small $\mathrm{m}^{\mathrm{R}} \mathrm{RE}^{\mathrm{m}}$ with a high $\mathrm{P}(\%)$ for two data sets that correlate well and a high $\mathrm{m} \% \mathrm{RE}^{\mathrm{m}}$ with a low $\mathrm{P}(\%)$ for data sets that do not correlate well. Furthermore, triangular actuator displacements of various frequencies and amplitudes are used. This result in large parts of the movement being at constant velocity that fulfils the assumptions of no inertial effects and a quasi-static gas compression process made in par. 2.1.2. It also keeps other factors such as friction, which is velocity dependent, constant during large parts of the tests and eliminates other possible transient effects.

\subsubsection{Soft spring}

During the experimental tests the pressure is measured at P2 for the soft spring (see Figure 1). The displacement of the actuator is shown in Figure 8 with the corresponding values given in Table 2. The simulated results for IG

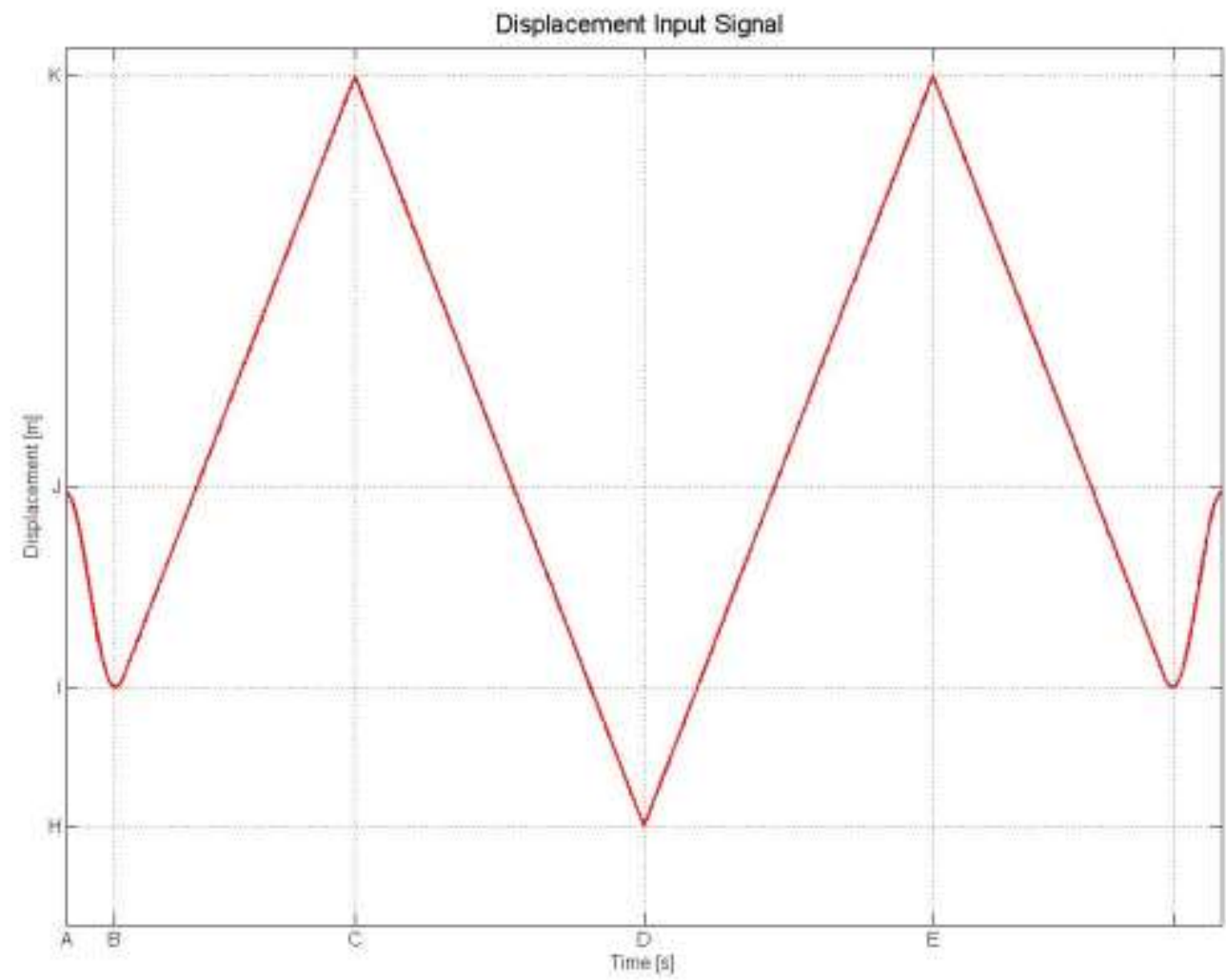

Figure 8 Displacement input signal

Table 2 Corresponding values for the soft suspension input signals

\begin{tabular}{|l|l|l|l|c|c|c|c|c|c|c|}
\hline $\begin{array}{c}\text { Signal Frequency } \\
{[\mathrm{Hz}]}\end{array}$ & $\begin{array}{c}\mathrm{A} \\
{[\mathrm{s}]}\end{array}$ & $\begin{array}{c}\mathrm{B} \\
{[\mathrm{s}]}\end{array}$ & $\begin{array}{c}\mathrm{C} \\
{[\mathrm{s}]}\end{array}$ & $\begin{array}{c}\mathrm{D} \\
{[\mathrm{s}]}\end{array}$ & $\begin{array}{c}\mathrm{E} \\
{[\mathrm{s}]}\end{array}$ & $\begin{array}{c}\mathrm{H} \\
{[\mathrm{m}]}\end{array}$ & $\begin{array}{c}\mathrm{I} \\
{[\mathrm{m}]}\end{array}$ & $\begin{array}{c}\mathrm{J} \\
{[\mathrm{m}]}\end{array}$ & $\begin{array}{c}\mathrm{K} \\
{[\mathrm{m}]}\end{array}$ & $\begin{array}{c}\text { Speed } \\
{[\mathrm{m} / \mathrm{s}]}\end{array}$ \\
\hline 0.001 & 0 & 89 & 500 & 1000 & 1500 & -0.117 & -0.081 & 0 & 0.075 & $0.38 \times 10^{-3}$ \\
\hline 0.1 & 0 & 0.98 & 5.1 & 10.1 & 15.1 & -0.117 & -0.081 & 0 & 0.075 & 0.0384 \\
\hline
\end{tabular}

isothermal, IG with EE and IE adiabatic are compared to measured results in Figure 9. For low speed inputs (Figure 9a), the isothermal approach gives good correlation but it deviates significantly from the experimental data at higher speed (Figure 9b). The adiabatic approach again gives good correlation for high frequency inputs 

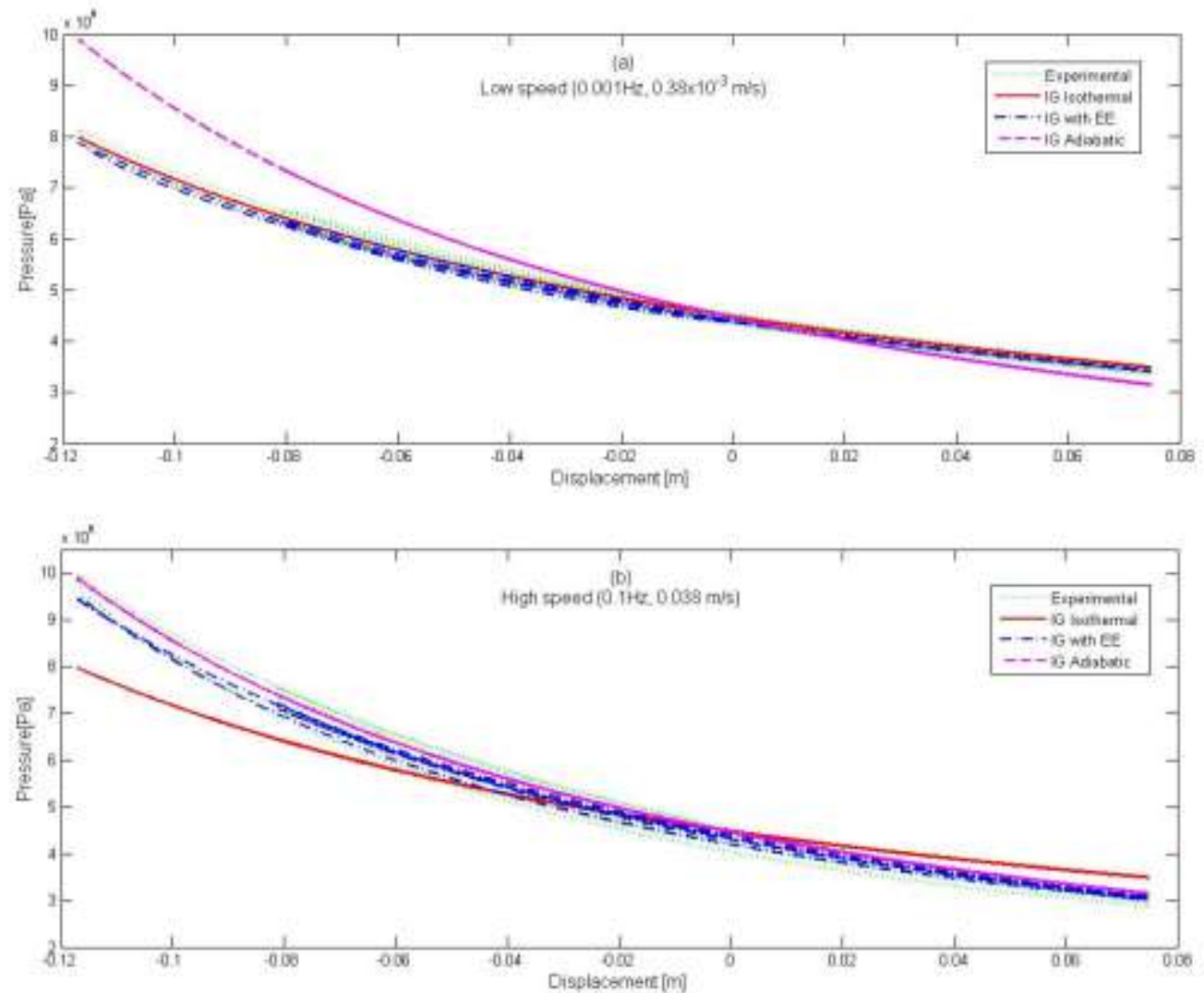

Figure 9 IG models compared to experiments (soft suspension)
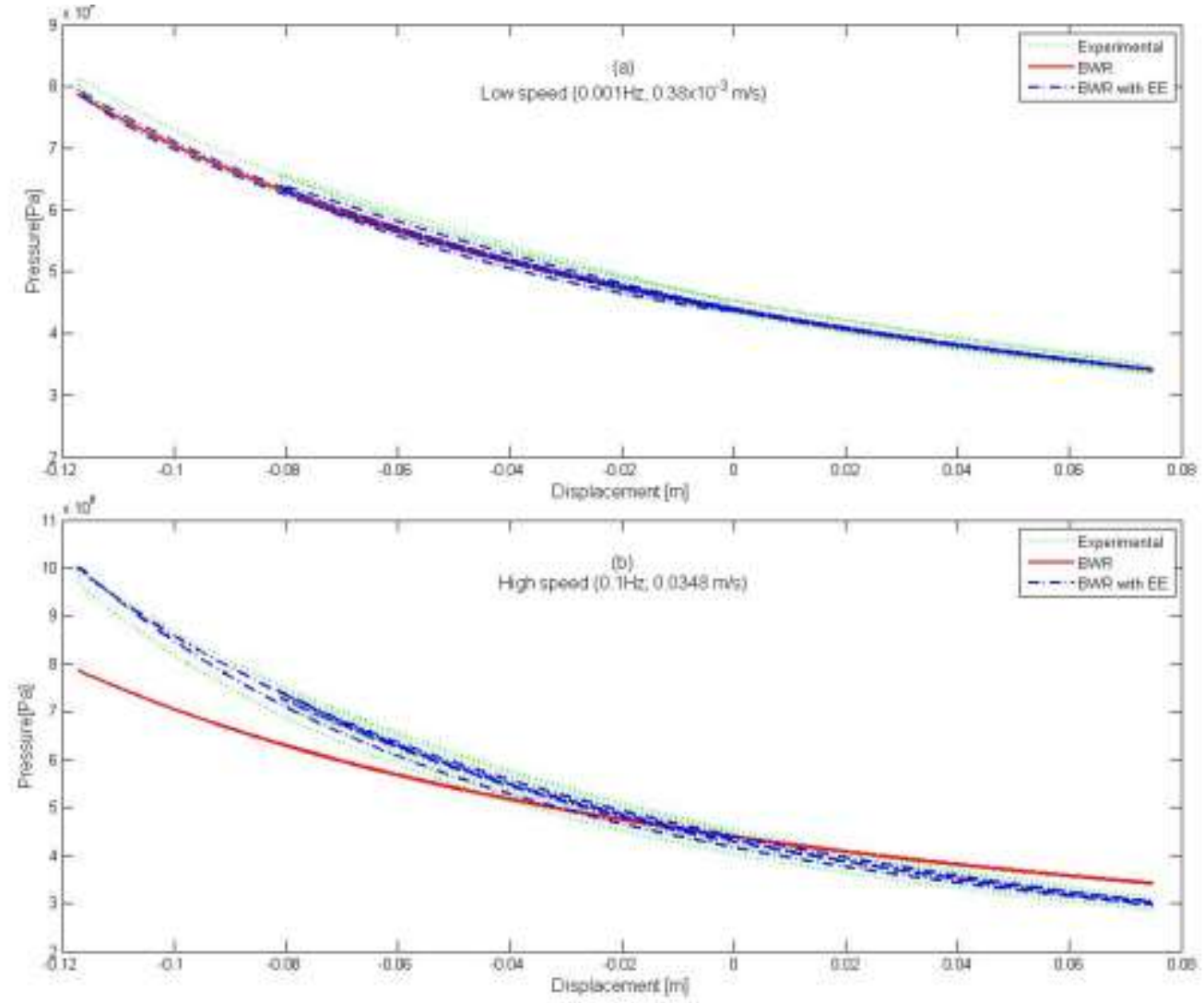

Figure 10 BWR models compared to experiments (soft suspension) 
(Figure 9b) but gives poor results at lower frequencies (Figure 9a). The inclusion of the EE results in a significant correlation improvement. Figure 10 indicates the comparison of BWR and BWR with EE to measured results for both low speed (Figure 10a) and high speed (Figure 10b). Again the use of the EE is crucial. Table 3 shows the average $\mathrm{m} \% \mathrm{RE}^{\mathrm{m}}$ for $P(95)$, for four the displacement inputs $(0.001,0.01,0.05$ and $0.1 \mathrm{~Hz}$ ). From Table 3 it is again clear that the inclusion of the EE results in a substantial improvement over the isothermal and adiabatic approaches. The inclusion of the EE provides a larger gain in accuracy compared to the relatively small additional gain in accuracy when using the real gas BWR model instead of the IG model.

Table $3 \mathrm{~m} \% \mathrm{RE}^{\mathrm{m}}$ values for the predicted gas pressure compared to measured gas pressure (soft suspension)

\begin{tabular}{|c|c|c|c|c|c|}
\hline & IG with EE & BWR with EE & IG Isothermal & BWR & IG Adiabatic \\
\hline Average $\left(\mathrm{m} \% \mathrm{RE}^{\mathrm{m}}\right) P(\%)$ & $5.48 P(95)$ & $4.94 P(95)$ & $12.52 P(95)$ & $11.63 P(95)$ & $14.34 P(95)$ \\
\hline
\end{tabular}

\subsubsection{Stiff spring}

During the experimental tests of the stiff spring the pressure was measured at P1, seeing that it is closer to the accumulator than P2 and only the small accumulator is used on the stiff setting (see Figure 1). The same triangular displacement signal was used (Figure 8) with the corresponding values given in Table 4 . The same

Table 4 Corresponding values for the stiff suspension input signals

\begin{tabular}{|l|l|l|l|l|l|l|l|l|l|l|}
\hline $\begin{array}{c}\text { Signal Frequency } \\
{[\mathrm{Hz}]}\end{array}$ & $\begin{array}{c}\mathrm{A} \\
{[\mathrm{s}]}\end{array}$ & $\begin{array}{c}\mathrm{B} \\
{[\mathrm{s}]}\end{array}$ & $\begin{array}{c}\mathrm{C} \\
{[\mathrm{s}]}\end{array}$ & $\begin{array}{c}\mathrm{D} \\
{[\mathrm{s}]}\end{array}$ & $\begin{array}{c}\mathrm{E} \\
{[\mathrm{s}]}\end{array}$ & $\begin{array}{c}\mathrm{H} \\
{[\mathrm{m}]}\end{array}$ & $\begin{array}{c}\mathrm{I} \\
{[\mathrm{m}]}\end{array}$ & $\begin{array}{c}\mathrm{J} \\
{[\mathrm{m}]}\end{array}$ & $\begin{array}{c}\mathrm{K} \\
{[\mathrm{m}]}\end{array}$ & $\begin{array}{c}\text { Speed } \\
{[\mathrm{m} / \mathrm{s}]}\end{array}$ \\
\hline 0.001 & 0 & 87 & 500 & 1000 & 1500 & -0.062 & -0.037 & 0 & 0.075 & $0.27 \times 10^{-3}$ \\
\hline 0.1 & 0 & 1.7 & 10.08 & 19.92 & & -0.06 & -0.037 & 0 & 0.075 & 0.0137 \\
\hline 2 & 0 & 0.096 & 0.28 & 0.54 & 0.79 & -0.048 & -0.017 & 0 & 0.055 & 0.4 \\
\hline
\end{tabular}

phenomenon as with the soft spring is displayed in Figure 11 and Figure 12 where it can be seen that the isothermal and adiabatic models are again only accurate for certain input signals. The average $\mathrm{m} \% \mathrm{RE}^{\mathrm{m}}$ at $P(95)$ for 5 signals $(0.001,0.01,0.05,0.1$ and $2 \mathrm{~Hz})$ is shown in Table 5. The EE gives superior simulation results compared to the isothermal and adiabatic models. The BWR model gives a relatively small improvement compared to the IG models. It can also been seen that the adiabatic process is already reached at a speed of $0.0137 \mathrm{~m} / \mathrm{s}(0.1 \mathrm{~Hz}$ as shown in Figure 11b). Increasing the speed to $0.4 \mathrm{~m} / \mathrm{s}(2 \mathrm{~Hz})$ decreases the size of the hysteresis loop but still follows the adiabatic line closely. The correlation for the smaller gas volume of the stiff spring is not as good as with the soft spring. The experimental data shows a significantly larger hysteresis loop than that captured by the gas models.

Table $5 \mathrm{~m} \% \mathrm{RE}^{\mathrm{m}}$ values for the predicted gas pressure compared to measured gas pressure (stiff suspension)

\begin{tabular}{|c|c|c|c|c|c|}
\hline & IG with EE & BWR with EE & IG Isothermal & BWR & IG Adiabatic \\
\hline Average $\left(\mathrm{m} \% \mathrm{RE}^{\mathrm{m}}\right) P(\%)$ & $15.49 P(95)$ & $13.61 P(95)$ & $28.93 P(95)$ & $28.54 P(95)$ & $21.00 P(95)$ \\
\hline
\end{tabular}

Figure 13 shows the isothermal IG model and the BWR model with the EE with the damper force included compared to experimental laboratory data. It is clear from the $2 \mathrm{~Hz}$ data (Figure 13c) that the accuracy of the damper model can have a significant effect on the correlation and that the damper model becomes less accurate at higher frequencies. It should be noted that the damper model is simply a lookup table - no temperature effects or hysteresis in the damper valves are included. Friction in the accumulator piston seals is also ignored. 

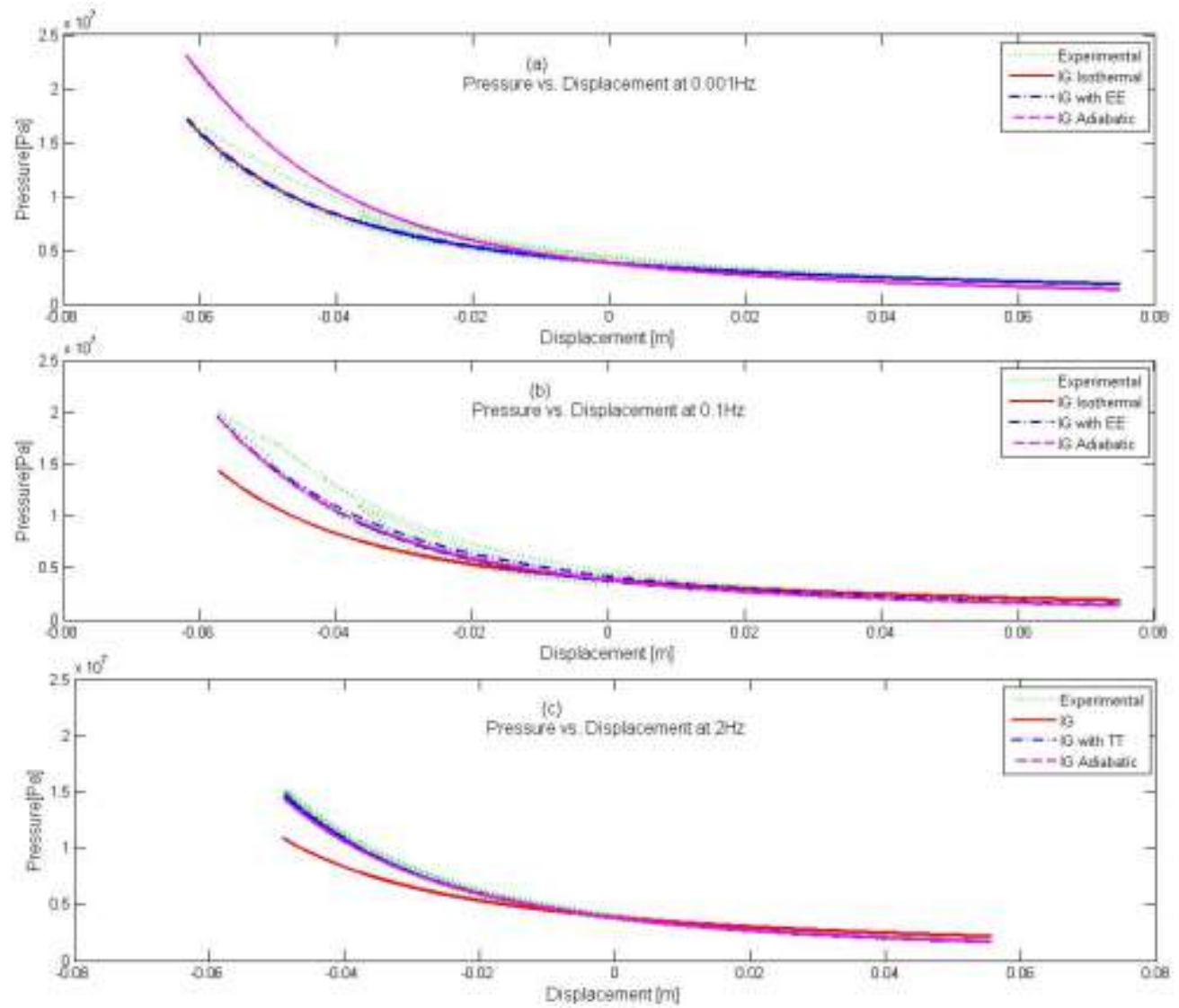

Figure 11 IG models compared to experiments (sfiff suspension)
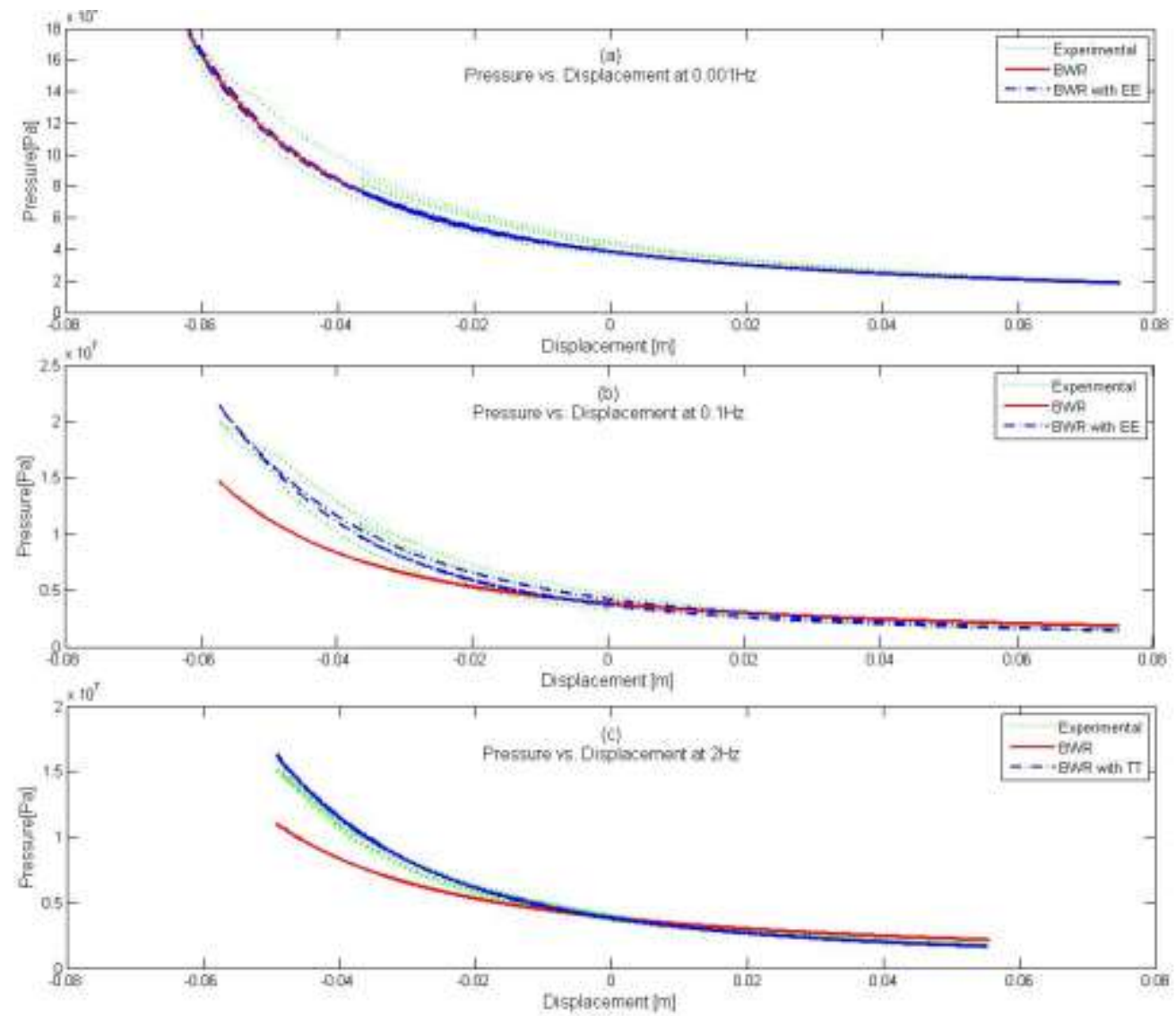

Figure 12 BWR models compared to experiments (stiff suspension) 

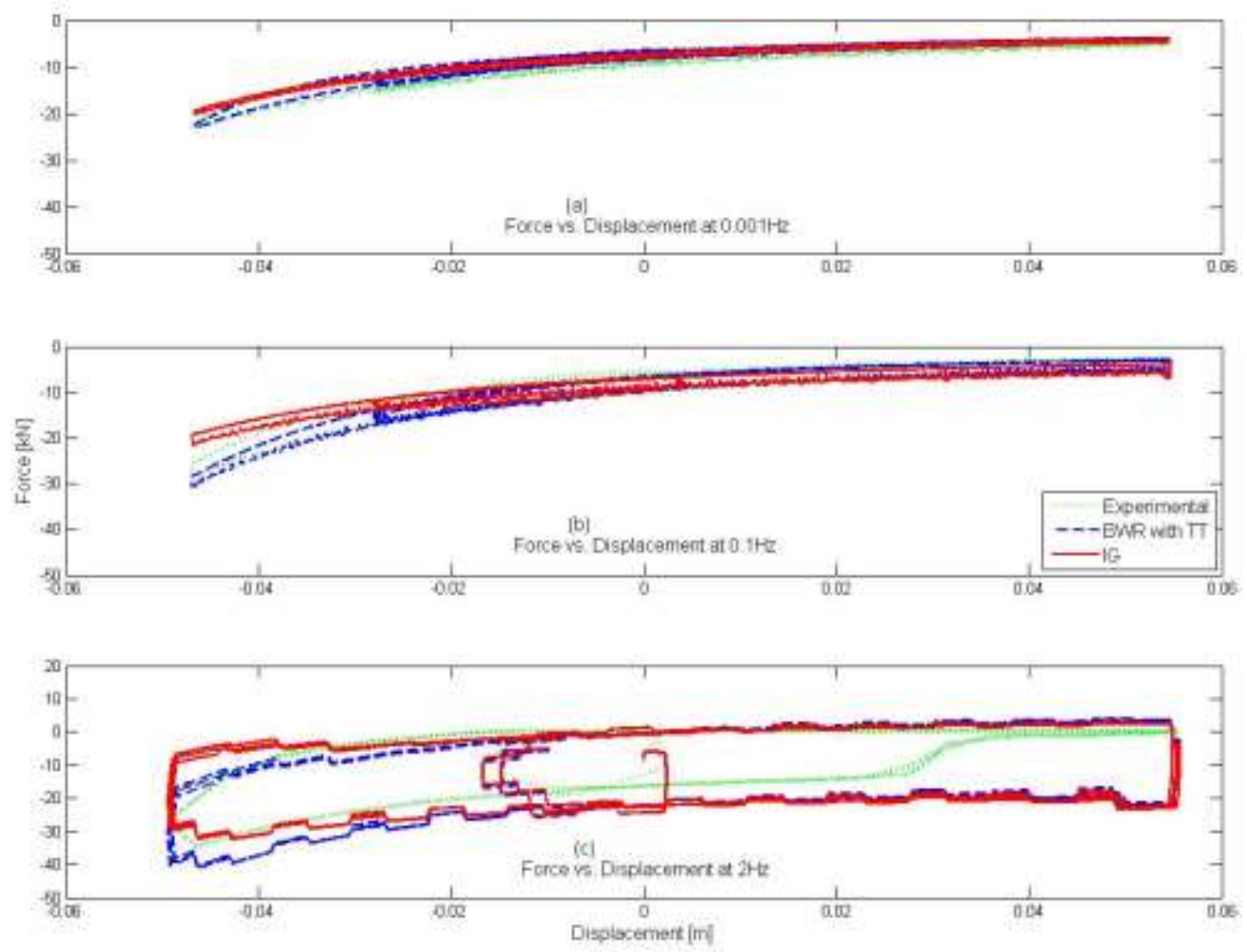

Figure 13 Simulation models compared to experimental data with the damper packs installed (stiff suspension)

\subsection{Vehicle tests}

Experimental vehicle testing was done by performing a double lane change (DLC) on a level concrete straight track at Gerotek Test Facilities near Pretoria in South Africa [22]. The DLC's were performed at speeds ranging from $50 \mathrm{~km} / \mathrm{h}$ to $75 \mathrm{~km} / \mathrm{h}$. The Land Rover Defender test vehicle was equipped with a VBOX III GPS [23] to record the path and speed of the vehicle. String displacement transducers were used to measure the suspension displacements and laser displacement transducers were fixed to each side of the vehicle to measure the body roll angle. Pressure transducers were used to measure the pressures in all four the suspension struts (P2 in Figure 1). Since the largest deviations are expected to take place at higher pressures and the errors caused by the vehicle model is smaller at smaller body roll angles, the full vehicle tests were performed with the $4 \mathrm{~S}_{4}$ on its handling setting (stiff spring and high damping).

The gas charging procedure is again extremely important here. To make sure that trapped air is bled out of the oil, the accumulator drain plugs are removed and the ride height of the suspension is adjusted several times from maximum to minimum. This process pushes all accumulator pistons to full compression, ensures that the units are filled with oil and that trapped air escapes. The accumulator drain plugs are then sealed. The gas charging procedure is automated by connecting each of the accumulators to the high pressure charging cylinder in turn using computer controlled solenoid valves. The computer measures the displacement of each suspension strut and slowly charges small amounts of gas into each accumulator in turn until the required static displacement is achieved. The pressure in the suspension system is thus determined by the load on each specific suspension strut. Because the vehicle is a statically indeterminate system, charging one accumulator results in a change of load and displacement on all the others. In addition, the other effects discussed in par. 3.1 (temperature, friction etc.) are still present. All these factors result in significant uncertainty about the actual gas mass charged into each accumulator.

\subsection{Suspension model validation against vehicle test results}

Using the vehicle model described in section 2.3 a DLC at $75 \mathrm{~km} / \mathrm{h}$ is simulated using the isothermal IG model and the BWR model with the EE to predict the pressure of the gas inside the hydropneumatic suspension units. 
The path and speed from the measured experimental data are used as inputs to the model. In par 3.3 the isothermal IG model was found to be the worst model while the BWR with the EE was the best model compared to the laboratory tests.

Initial simulation results did not correlate well with the experimental data. It was discussed before that, during the gas charging procedure of the suspension units, the actual amount of gas charged can differ. In order to get improved results with the model, the gas volumes, static pressures and ambient temperature was optimised, for each suspension unit individually, by minimizing the error between the predicted pressure (P2) for the suspension model and the equivalent pressure measured during the experimental DLC tests. For this optimisation the BWR spring model with the EE was given the experimentally measured suspension displacement as input. The optimization yielded the results shown in Table 6 , and typical pressure data is shown in Figure 14. It can be seen that the model can predict the pressure with good accuracy as was concluded in par

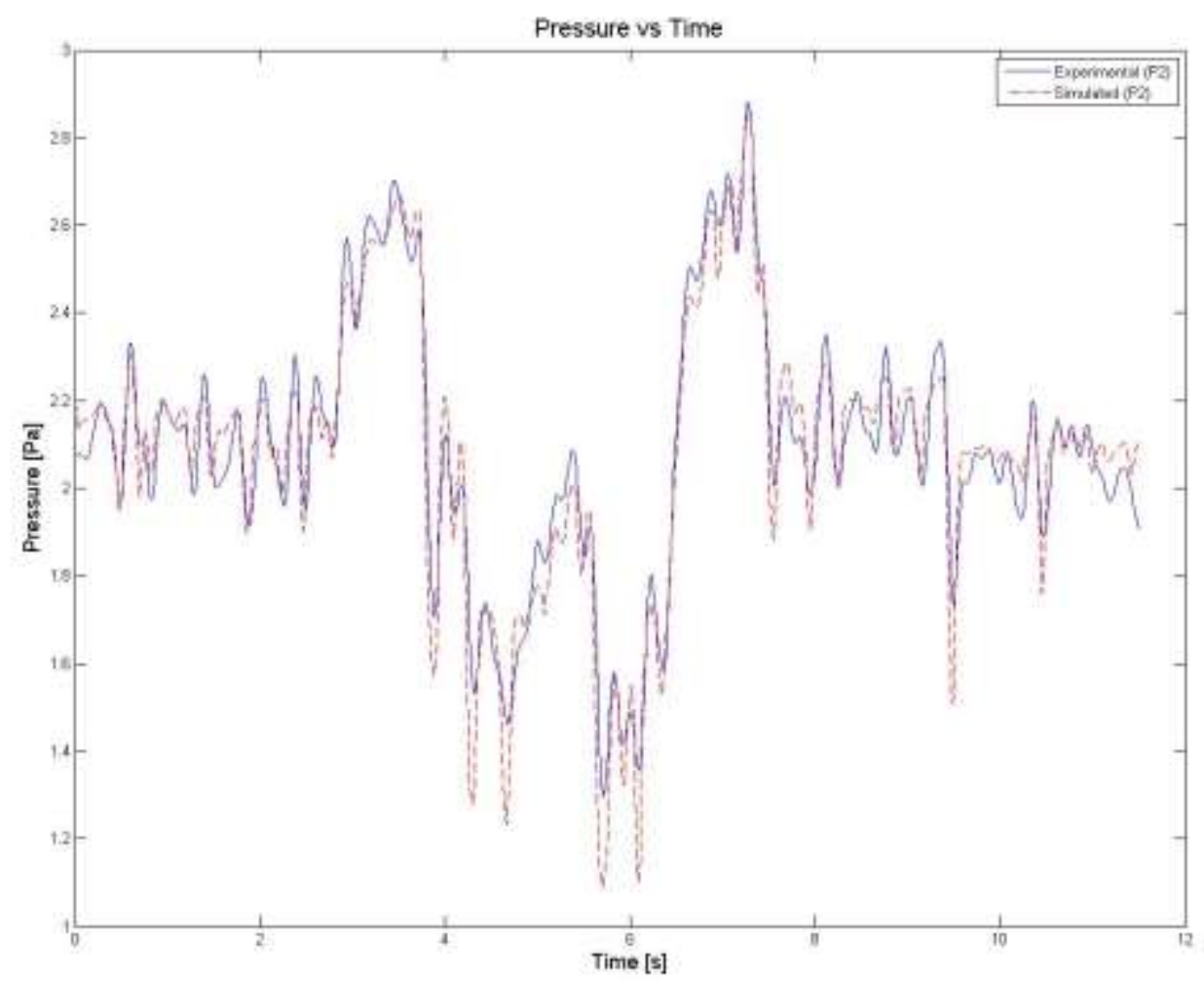

Figure 14 Optimised Left Front BWR model with EE compared to experimental data, using the experimental displacement as input

Table 6 Stiff suspension optimisation results

\begin{tabular}{|c|c|c|c|c|}
\hline & Left Front & Right Front & Left Rear & Right Rear \\
\hline Static Gas Volume $[\ell]$ & 0.0737 & 0.116 & 0.0998 & 0.0739 \\
\hline Static Pressure $[\mathrm{Pa}]$ & $2.28 \mathrm{E}+06$ & $2.82 \mathrm{E}+06$ & $3.08 \mathrm{E}+06$ & $2.47 \mathrm{E}+06$ \\
\hline Ambient Temperature $[\mathrm{K}]$ & 290.4 & 296.9 & 294.7 & 297.4 \\
\hline
\end{tabular}

The optimisation results in Table 6 show that the temperature variation between the four suspension sets are small. The temperature was therefore taken as the average temperature $(T \approx 295 \mathrm{~K})$ for all the units. The static pressures and volumes determined were used to calculate the amount of gas in the suspension units. This data was then used in the full vehicle model to model the performed DLC (at $75 \mathrm{~km} / \mathrm{h}$ ).

Typical pressure results for the BWR model with the EE and the IG isothermal model are shown in Figure 15 and Figure 16. The pressure data is used to validate the models and not the displacement data, because the pressure data will include the least amount of external errors (e.g. due to friction or damping). The pressure was 


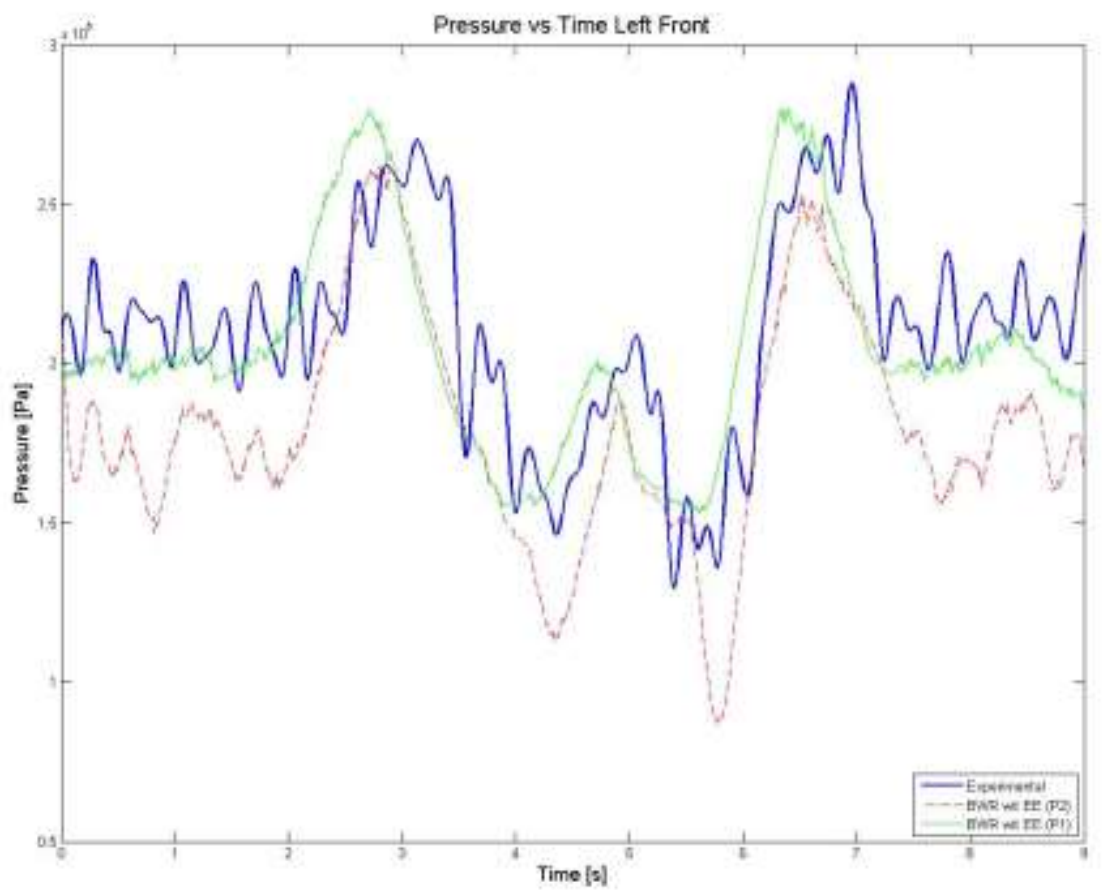

Figure 15 BWR with EE simulated pressure compared to measured pressure data for the left front strut

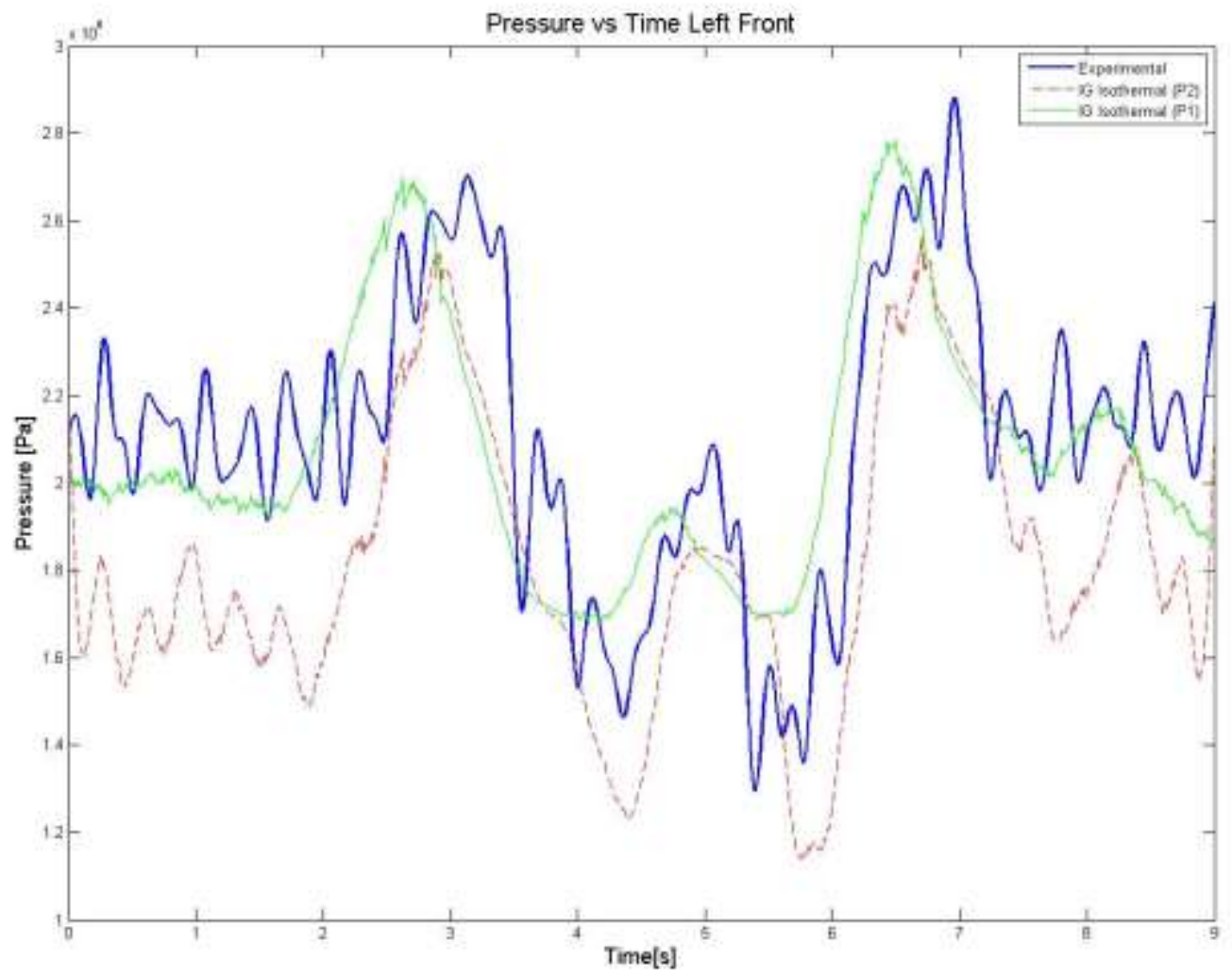

Figure 16 IG isothermal simulated pressure compared to measured pressure data for the left front strut

measured at P2 (see Figure 1) during the experimental tests. This means that the pressure difference due to the damper pack needs to be subtracted from the spring force in the model to get the pressure at $\mathrm{P} 2$. This does however mean that the accuracy of the damper model will affect the results, and there will also be a friction 
force present due to the friction of the floating piston, but this is currently neglected. The correlation for the full vehicle model (Figure 15 and 16) is not as good as was obtained during the optimisation runs (Figure 14). This is due to uncertainties in the vehicle model for instance the position of the CG will affect the static pressure as well as the dynamic pressures. The effect of this can be seen in the data for the left front unit (Figure 15) where the static pressure of the model is lower than the measured pressure. Due to these un-modelled effects and inaccuracies in the full vehicle model, poor correlation is achieved.
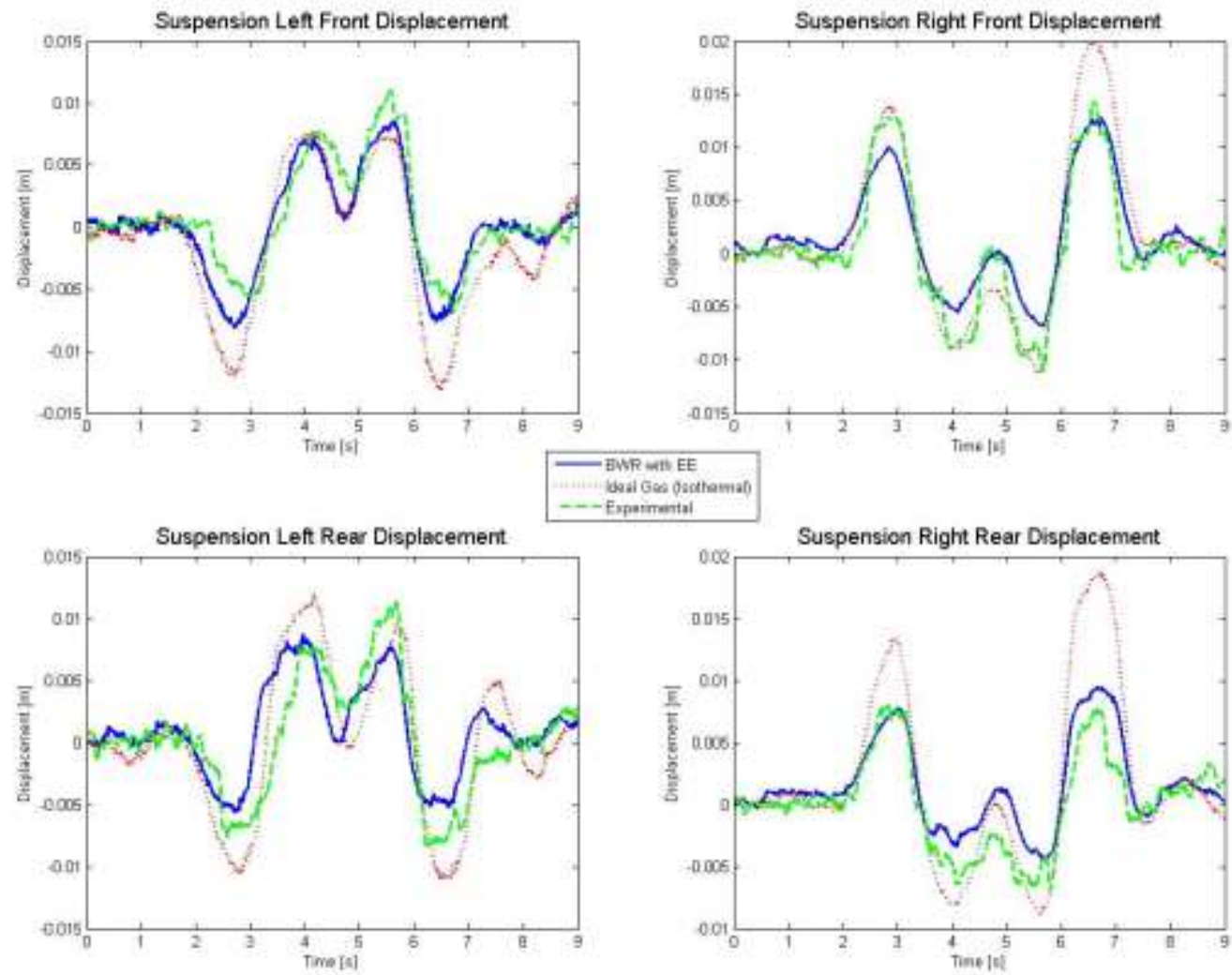

Figure 17 Suspension displacements of the IG (Isothermal) and BWR (With EE) models vs. experimental results

Table $7 \mathrm{~m} \% \mathrm{RE}^{\mathrm{m}}$ for IG and BWR pressures compared to the experimental results

\begin{tabular}{|c|c|c|c|c|c|}
\hline & Left Front & Right Front & Left Rear & Right Rear & Average \\
\hline & $\mathrm{m} \% \mathrm{RE}^{\mathrm{m}}$ & $\mathrm{m} \% \mathrm{RE}^{\mathrm{m}}$ & $\mathrm{m} \% \mathrm{RE}^{\mathrm{m}}$ & $\mathrm{m} \% \mathrm{RE}^{\mathrm{m}}$ & $\mathrm{m}^{\mathrm{R}} \mathrm{RE}^{\mathrm{m}}$ \\
\hline IG (Isothermal) & $27.39 P(95)$ & $23.06 P(95)$ & $23.54 P(95)$ & $35.64 P(95)$ & $27.41 P(95)$ \\
\hline BWR with EE & $29.00 P(95)$ & $15.39 P(95)$ & $16.64 P(95)$ & $23.97 P(95)$ & $21.25 P(95)$ \\
\hline
\end{tabular}

Table $8 \mathrm{~m} \% \mathrm{RE}^{\mathrm{m}}$ for IG and BWR displacement compared to the experimental results

\begin{tabular}{|c|c|c|c|c|c|}
\hline & Left Front & Right Front & Left Rear & Right Rear & Average \\
\hline & $\mathrm{m} \% \mathrm{RE}^{\mathrm{m}}$ & $\mathrm{m} \% \mathrm{RE}^{\mathrm{m}}$ & $\mathrm{m} \% \mathrm{RE}^{\mathrm{m}}$ & $\mathrm{m} \% \mathrm{RE}^{\mathrm{m}}$ & $\mathrm{m}^{\mathrm{R}} \mathrm{RE}^{\mathrm{m}}$ \\
\hline IG (Isothermal) & $71.78 P(40.84)$ & $63.85 P(48.83)$ & $77.46 P(35.07)$ & $80.82 P(34.63)$ & $73.48 P(39.84)$ \\
\hline BWR with EE & $63.05 P(47.95)$ & $65.24 P(47.95)$ & $64.45 P(47.28)$ & $64.23 P(49.61)$ & $64.24 P(48.20)$ \\
\hline
\end{tabular}

The $\mathrm{m} \% \mathrm{RE}^{\mathrm{m}}$ values for a $95 \%$ probability is calculated and shown in Table 7 . For the $95 \%$ probability of the data the BWR model with the EE results in a $22.5 \%$ smaller average $\mathrm{m} \% \mathrm{RE}^{\mathrm{m}}$ compared to the IG isothermal model. Figure 17 shows the displacement results for the discussed data, and from Table 8 it can again be seen that there is a significant reduction in the $\mathrm{m} \% \mathrm{RE}^{\mathrm{m}}$. The displacement data does however include all the forces shown in Figure 2 and therefore is not suitable for determining the accuracy of only the gas models. Irrespective of this the displacement data still shows that the BWR model with the EE correlates significantly better with the 
experimental data than the IG isothermal model. Differentiating the suspension displacements indicated in Figure 17 indicate maximum suspension speeds of around $0.04 \mathrm{~m} / \mathrm{s}$ which correspond to the speeds obtained at $0.1 \mathrm{~Hz}$ for the soft suspension as indicated in Table 2.

\section{Conclusions and recommendations}

An extensive amount of work was done by [6], [9] and [10] showing the superior performance obtained when using the EE but the quantity of the improvement was never clear. This study used subsets of the data to show the improvement possible in a vehicle dynamics application.

From the laboratory tests it can be concluded that the BWR model with the EE gives the best correlation, and this model will be recommended for high accuracy applications. The IG models, combined with the EE, are only slightly less accurate than the BWR models, indicating that the IG assumption is valid for the specific conditions investigated in this paper. For cases where the displacement accuracy is not critical, both isothermal approaches will give sufficient accuracy at lower frequency excitations and the adiabatic approach will give good correlation at higher frequency excitations.

From the full vehicle simulation and experimental data, it can be seen that a significant improvement in correlation is possible with the BWR model with the EE. It should also be noted that a DLC excites the suspension within the speed range (at low frequencies) where the BWR model with the EE yields significantly better results than either adiabatic or isothermal models. With all models it is crucial to use the correct gas mass (static volume and pressure). The gas mass can be determined by means of an optimisation as was done in this study. The gas charging procedure should also be improved to ensure that all the accumulators are charged with the required mass of gas within an acceptable tolerance. This might require accurate measurement of the temperature and pressure in each accumulator as well as the displacement of each accumulator piston.

More detailed studies should be performed to validate the models under varying operating conditions where some of the uncertain parameters, e.g. gas and oil temperatures as well as friction, can be better controlled or measured. Friction plays an important role in hydropneumatic suspensions systems and additional efforts should be made to quantify and model friction.

$\begin{array}{ll}\text { Abbreviations } \\ \text { BWR } & \text { Benedict Webb Rubin } \\ \text { DLC } & \text { Double lane change } \\ \text { EE } & \text { Energy equation } \\ \text { IG } & \text { Ideal gas } \\ \text { RE } & \text { Relative error } \\ \text { SUV } & \text { Sports Utility Vehicle }\end{array}$

\section{Nomenclature}

$a$

$\mathrm{A}_{\mathrm{o}}$

$\mathrm{b}$

$\mathrm{B}_{\mathrm{o}}$

C

$c_{v}^{o}$

$c_{v}$

$\mathrm{C}_{\mathrm{o}}$

$h$

$m$

$n \quad$ Polytropic constant

$\mathrm{N}_{1}$ to $\mathrm{N}_{9} \quad$ Specific heat constants
BWR constant

BWR constant

BWR constant

BWR constant

BWR constant

Ideal gas specific heat constant

Specific heat constant

BWR constant

Time step

Mass 


$\begin{array}{ll}\mathrm{P} & \text { Pressure (Subscripts: } 1 \text { - Initial state, } 2 \text { - Current state) } \\ \dot{\mathrm{Q}} & \text { Heat transfer rate between the system and the environment } \\ R & \text { Universal gas constant } \\ t & \text { Time } \\ \mathrm{T} & \text { Temperature (Subscripts: } 1 \text { - Initial state, } 2 \text { - Current state) } \\ \mathrm{T}_{\mathrm{s}} & \text { Atmospheric temperature } \\ T_{g} & \text { Gas temperature } \\ \dot{T}_{g} & \text { Change in gas temperature } \\ \dot{\mathrm{u}} & \text { Change in specific internal energy of the gas } \\ \dot{\mathrm{U}} & \text { Change in internal energy of the gas } \\ \dot{v} & \text { Change in specific volume } \\ v & \text { Specific volume } \\ \dot{\mathrm{V}} & \text { Change of volume } \\ V & \text { Volume (Subscripts: } 1 \text { - Initial state, } 2 \text { - Current state) } \\ V_{o} & \text { Initial volume } \\ \dot{\mathrm{W}} & \text { Work done by the piston on the gas } \\ \mathrm{y} & \text { Specific heat constant } \\ \mathrm{m} \% \mathrm{RE}^{\mathrm{m}} & \text { Modified mean percentage relative error } \\ P(\%) & \text { Probability }\end{array}$

\section{Greek symbols}

$\begin{array}{ll}\alpha & \text { BWR constant } \\ \beta & \text { Bulk modulus } \\ \gamma & \text { BWR constant or adiabatic index (context dependant) } \\ \tau & \text { Thermal time constant } \\ \Delta \mathrm{P} & \text { Change in pressure } \\ \Delta \mathrm{V} & \text { Change in volume }\end{array}$

\section{References}

[1] Kat, C.-J. and Els, P.S., 2012, Validation metric based on relative error, Mathematical and Computer Modelling of Dynamical Systems: Methods, Tools and Applications in Engineering and Related Sciences, Volume 18, Issue 5, 2012, pp. 487-520.

[2] Bernard, J. and Clover, C., 1994, Validation of Computer Simulations of Vehicle Dynamics, SAE Technical Paper 940231, SAE International, Warrendale, PA, 1994.

[3] Bauer, W., 2011, Hydropneumatic Suspension Systems, Springer, Heidelberg, 2011

[4] V.S.E., 2013, Suspension: DTS, http://www.v-s-e.nl/products/suspension/suspension-dts.html?L=1, Accessed: 4 September 2013.

[5] Van der Westhuizen S.F., and Els, P.S., 2013,Slow active suspension control for rollover prevention, Journal of Terramechanics, Volume 50, Issue 1, February 2013, pp. 29 - 36.

[6] Els, P. S., 2006, The ride comfort vs. handling compromise for off-road vehicles, Unpublished PhD thesis, University of Pretoria, Pretoria, http://upetd.up.ac.za/thesis/available/etd-07152008-102911/, Accessed: 7 June 2011.

[7] Deprez, K., Maertens, K. and Ramon, H., 2002, Comfort Improvement by Passive and Semi-Active Hydropneumatic Suspension Using Global Optimization Technique, Proceedings of the American Control conference, Anchorage, AK, May 8-10, 2002.

[8] Cooke, R., Crolla, D.A., and Abe, B., 1997,Modeling Combined Ride and Handling Manoeuvres for a Vehicle with Slow-Active Suspension, Vehicle System Dynamics, International Journal of Vehicle Mechanics and Mobility, 27:5-6, 457-476, 1997.

[9] Otis. D.R. and Pourmovahed, A., 1985, An Algorithm for Computing Nonflow Gas Processes in Gas Springs and Hydropneumatic Accumulators, Transactions of the ASME, Journal of Dynamic Systems, Measurement and Control, Volume 107, March 1985, pp.110-118 
[10] Els, P. and Grobbelaar, B., 1993, Investigation of the Time- and Temperature Dependency of HydroPneumatic Suspension Systems, SAE Technical Paper 930265, 1993.

[11] Sontag, R. E., Borgnakke, C. and Van Wylen, G. J., 1991, Introduction to thermodynamics, 3rd ed., John Wiley and Sons, New York, 1991.

[12] Cheney, W. and Kincaid, D., 2004, Numerical Mathematics and Computing, Brooks/Cole-Thomas Learning, Belmont, 2004

[13] Thoresson, M. J., 2007, Efficient gradient-based optimisation of suspension characteristics for an offroad vehicle, Unpublished $\mathrm{PhD}$ thesis, University of Pretoria, Pretoria, South Africa, upetd.up.ac.za/thesis/available/etd-08042008-093103/, Accessed: 5 June 2012

[14] MathWorks, 2012, MATLAB - The Language of Technical Computing, http://www.mathworks.com/products/matlab/, Accessed: 05 January 2012.

[15] MathWorks, 2011, Simulink - Simulation and Model-Based Design, http://www.mathworks.com/products/simulink/, Accessed: 31 May2011.

[16] MSC.Software, 2011, ADAMS Multibody Dynamics, http://www.mscsoftware.com/Products/CAETools/Adams.aspx, Accessed: 30 May 2011.

[17] Uys, P.E., Els, P.S. and Thoresson, M.J., 2007, Suspension settings for optimal ride comfort of off-road vehicles travelling on roads with different roughness and speeds, Journal of Terramechanics, Vol. 44, pp. $163-175,2007$

[18] Cronje, P. H., 2008, Improving off-road vehicle handling using an active anti-roll bar, Unpublished Masters thesis, University of Pretoria, Pretoria, http://upetd.up.ac.za/thesis/available/etd-11262009011206/unrestricted/dissertation.pdf, Accessed 2 August 2012.

[19] Botha, T. R., 2011, High Speed Autonomous Off-Road Vehicle Steering, Unpublished Masters thesis, University of Pretoria, Pretoria, http://upetd.up.ac.za/thesis/available/etd-11212011-

125411/unrestricted/dissertation.pdf, Accessed 2 August 2012.

[20] Pacejka, H.B., 2002, Tyre and Vehicle Dynamics, Society of Automotive Engineers, Warrendale, USA 2002.

[21] Uys, P.E., Els, P.S., Thoresson, M.J., Voigt, K.G., Combrinck, W.C., 2006, Experimental Determination of Moments of Inertia for an Off-Road Vehicle in a Regular Engineering Laboratory, International Journal of Mechanical Engineering Education 34/4, 2006.

[22] Gerotek, 2012, Gerotek Test http://www.armscordi.com/SubSites/Gerotek/Gerotek01_landing.asp, Accessed 28 April 2012

[23] Racelogic, 2012, About Racelogic, http://www.racelogic.co.uk/?show=VBOX, Accessed 28 April 2012.

\section{Appendix A BWR and nitrogen constants [10]}

Constants for the BWR equation

$$
\begin{array}{ll}
a=0.115703387 & {\left[\left(\frac{\mathrm{m}^{3}}{\mathrm{~kg}}\right)^{3} \cdot \frac{\mathrm{N}}{\mathrm{m}^{2}}\right]} \\
A_{o}=136.0474619 & {\left[\left(\frac{\mathrm{m}^{3}}{\mathrm{~kg}}\right)^{3} \cdot \frac{\mathrm{N}}{\mathrm{m}^{2}}\right]} \\
b=2.96625 \times 10^{-6} & {\left[\left(\frac{\mathrm{m}^{3}}{\mathrm{~kg}}\right)^{3}\right]} \\
B_{o}=0.001454417 & {\left[\left(\frac{\mathrm{m}^{3}}{\mathrm{~kg}}\right]\right.} \\
c=7.3806143 \times 10^{-5} & \left.\left[\frac{\mathrm{m}^{3}}{\mathrm{~kg}}\right)^{3} \cdot \mathrm{K}^{2} \cdot \frac{\mathrm{N}}{\mathrm{m}^{2}}\right]
\end{array}
$$




$$
\begin{array}{ll}
C_{o}=1.0405873 \times 10^{-6} & {\left[\left(\frac{\mathrm{m}^{3}}{\mathrm{~kg}}\right)^{3} \cdot \mathrm{K}^{2} \cdot \frac{\mathrm{N}}{\mathrm{m}^{2}}\right]} \\
\alpha=5.7863972 \times 10^{-9} & {\left[\left(\frac{\mathrm{m}^{3}}{\mathrm{~kg}}\right)^{3}\right]} \\
\gamma=6.7539311 \times 10^{-6} & {\left[\left(\frac{\mathrm{m}^{3}}{\mathrm{~kg}}\right)^{2}\right]} \\
R=296.797 & {\left[\frac{\mathrm{J}}{\mathrm{kg} \cdot \mathrm{K}}\right]}
\end{array}
$$

Constants for the calculation of the IG specific heat capacity (Temperature in Kelvin)
$N_{1}=-735.210$
$N_{2}=34.224$
$N_{3}=-0.557648$
$N_{4}=3.5040$
$N_{5}=-1.7339 \times 10^{-5}$
$N_{6}=1.7465 \times 10^{-8}$
$N_{7}=-3.5689 \times 10^{-12}$
$N_{8}=1.0054$
$N_{9}=3353.4061$ 